\title{
Modeling Mechanical Behavior of a Prismatic Replaceable Reflector Block
}

Robert L. Bratton

April 2009

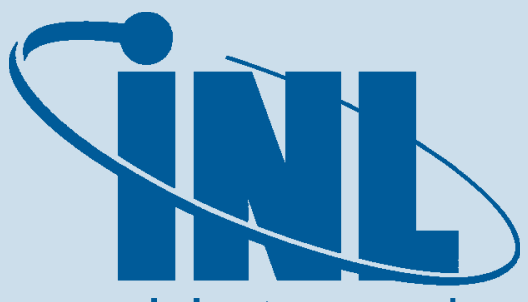

Idaho National Laboratory

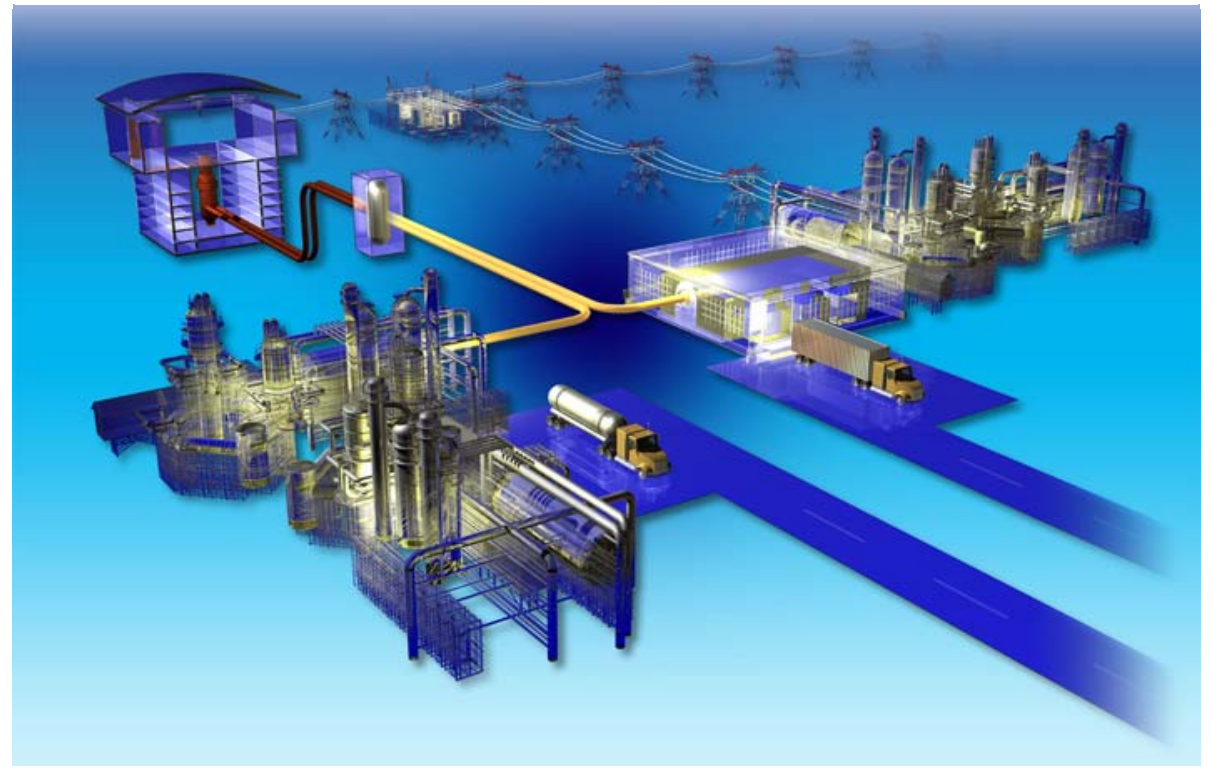

The INL is a U.S. Department of Energy National Laboratory operated by Battelle Energy Alliance. 


\section{DISCLAIMER}

This information was prepared as an account of work sponsored by an agency of the U.S. Government. Neither the U.S. Government nor any agency thereof, nor any of their employees, makes any warranty, expressed or implied, or assumes any legal liability or responsibility for the accuracy, completeness, or usefulness, of any information, apparatus, product, or process disclosed, or represents that its use would not infringe privately owned rights. References herein to any specific commercial product, process, or service by trade name, trade mark, manufacturer, or otherwise, does not necessarily constitute or imply its endorsement, recommendation, or favoring by the U.S. Government or any agency thereof. The views and opinions of authors expressed herein do not necessarily state or reflect those of the U.S. Government or any agency thereof. 


\title{
Modeling Mechanical Behavior of a Prismatic Replaceable Reflector Block
}

\author{
Robert L. Bratton
}

April 2009

Idaho National Laboratory

Next Generation Nuclear Plant Project

Idaho Falls, Idaho 83415

Prepared for the

U.S. Department of Energy

Office of Nuclear Energy

Under DOE Idaho Operations Office

Contract DE-AC07-05ID14517 

Next Generation Nuclear Plant Project

Modeling Mechanical Behavior of a Prismatic Replaceable Reflector Block

INL/EXT-09-15868

Revision 0

April 2009

Approved by:

Rater Buster

Robert Baton

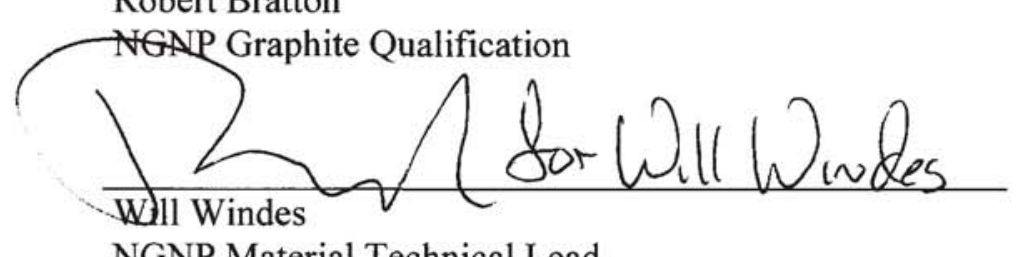

NGNP Material Technical Lead

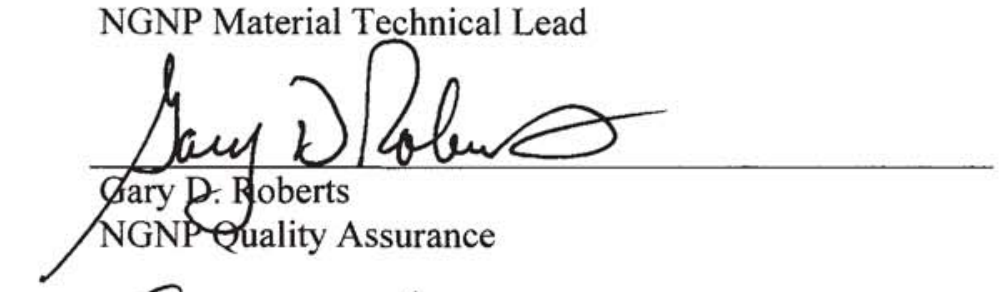

for Diane Cresol

Diane V Croon
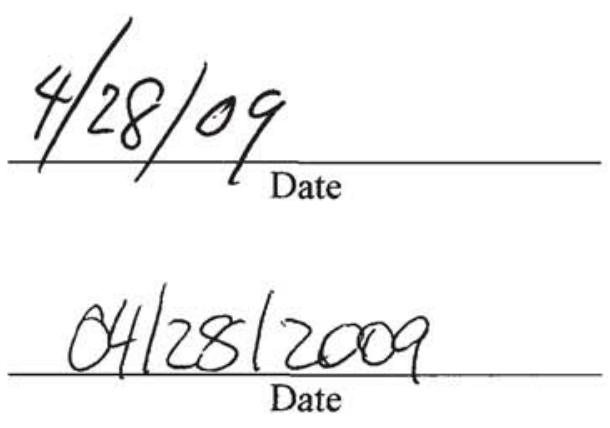

$$
04 / 28 / 2009
$$

$04 / 29 / 2009$ 



\begin{abstract}
This report outlines the development of finite element models used to determine temperature and stresses in a prismatic core reflector block. This initial analysis determines an appropriate temperature distribution in a prismatic reflector from limiting conditions in the adjacent fuel block based on simplifying assumptions. Sources are presented for the assumed core geometry, the reactor conditions, and the material properties used for the reference grade nuclear graphite (H-451). A description of the commercially available COMSOL finite element code used to create the models and the boundary conditions used within the models to calculate the temperatures in fuel and reflector blocks are discussed. Key operation parameters, such as the temperature and fluence distribution through a graphite reflector block, are quantified. The important material parameters and the effect neutron creep and irradiation dimension strains have upon them are identified. These critical input parameters are necessary in order for the model to predict stresses and strains generated within the reflector block and to predict graphite core component lifetimes. Finally, a discussion is included describing neutron irradiation creep and the importance of its inclusion in finite element modeling to predict core component lifetimes.
\end{abstract}




\section{CONTENTS}

ABSTRACT

ACRONYMS

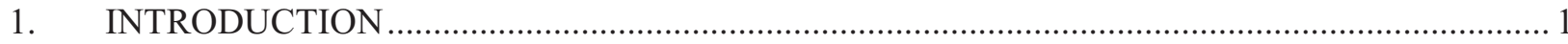

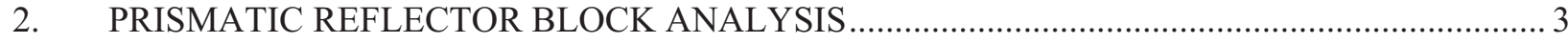

2.1 Reflector Block Graphite Properties ................................................................................. 5

2.2 Temperature Analysis in the Reflector Block ................................................................... 10

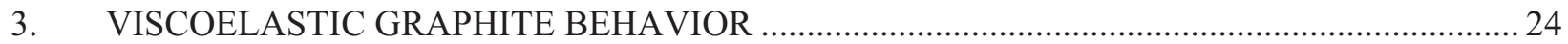

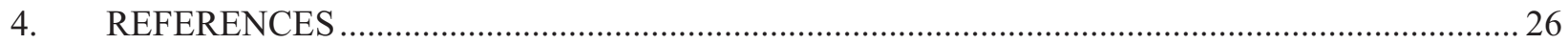

\section{FIGURES}

Figure 1. Core configuration of the conceptual design GT-MHR ........................................................ 2

Figure 2. Location of the selected reflector block being analyzed.......................................................... 3

Figure 3. Dimensions of the outer reflector block used in the analysis. .................................................. 4

Figure 4. Finite element mesh of the reflector block cross section..........................................................5

Figure 5. Temperature and fast neutron fluence through the reflector block.......................................... 6

Figure 6. H-451 thermal expansion in the axial direction as a function of irradiation temperature

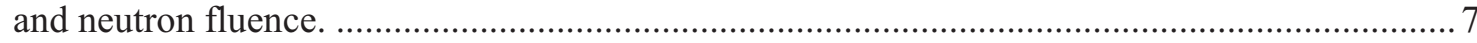

Figure 7. H-451 radial Young's modulus as a function of radial and axial distance in the billet

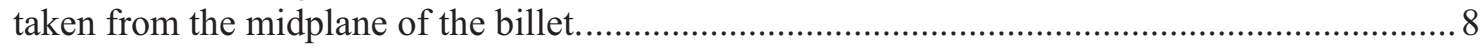

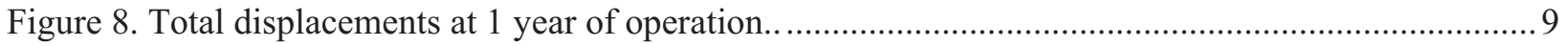

Figure 9. Total displacements at 5 years of operation......................................................................

Figure 10. a,b,c. Fast neutron fluence from the top and side fuel block crossing the perimeter at 6

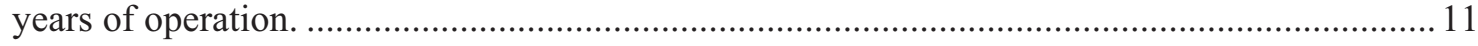

Figure 11. Gamma heat distribution in the reflector block. ............................................................. 12

Figure 12. Heat sources for the prismatic reflector block cross section being examined ......................... 13

Figure 13. Prismatic fuel element with one-twelfth sector cross section superimposed........................... 14

Figure 14. One-twelfth sector cross-section model.......................................................................... 15

Figure 15. Graphite temperature in the one-twelfth sector cross-section model .................................... 16

Figure 16. One-twelfth fuel sector cross section showing temperatures of fuel and graphite .................. 16

Figure 17. Plot of heat flux leaving and entering the lower boundary of the one-twelfth fuel sector

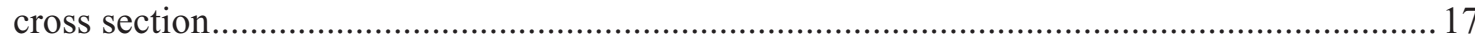

Figure 18. Model of a half fuel element cross section. Only half of the fuel element is modeled due to symmetry 18 
Figure 19. Temperature in the half fuel element cross-section model................................................. 19

Figure 20. Graphite temperature distribution in the fuel element cross section. ......................................20

Figure $21 \mathrm{a}$ and $\mathrm{b}$. Fuel element cross-section perimeter temperature and heat flux. ............................. 20

Figure $22 \mathrm{a}, \mathrm{b}$, and c. Temperature imposed on the reflector cross-section boundaries ...........................21

Figure 23. Temperature distribution in the reflector cross section with boundary temperatures

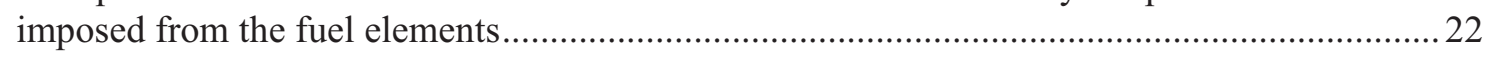

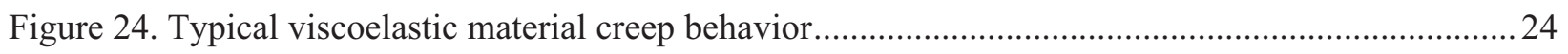




\section{ACRONYMS}

COMSOL Registered Trade Name from COMSOL AB

GA General Atomics

GT-MHR Gas Turbine Modular Helium Reactor

HTGR High Temperature Gas Reactor

INL Idaho National Laboratory

NGNP Next Generation Nuclear Plant

SMiRT Structural Mechanics in Reactor Technology

VHTR Very High Temperature Reactor 


\section{Modeling Mechanical Behavior of a Prismatic Replaceable Reflector Block}

\section{INTRODUCTION}

Prismatic reactors cores are assembled from machined hexagonal graphite blocks into a cylindrical core configuration as shown in Figure 1. The core is divided into three regions where the center is assembled from blocks without fuel or control rod channels; this region is denoted as the inner reflector. The next section is annular and is assembled with blocks containing fuel compacts and coolant holes drilled through the graphite blocks. This annular region is the active core of the reactor. A small number of fuel blocks contain control rod channels. The next annular section is the outer reflector region. This region contains graphite blocks with and without control rod channels.

Because of neutron moderation in the graphite, a steep temperature and fast neutron gradient is experienced on the face of the reflector blocks directly adjacent to the annular core region. Both irradiation damage from the fast neutron flux and the steep temperature gradient existing from the face will significantly affect the graphite block performance. Any degradation must be modeled to ensure safety and functional requirements can be satisfied during expected lifetimes of the block. Reflector blocks are assumed to be replaced when they no longer meet design margins. Ensuring safety and functional requirements are satisfied between reflector block replacements requires a material performance model to be constructed that analyzes the state of deformations, stress, and strain in the block to demonstrate compliance with design margins.

As discussed in DOE-HTGR-86-058, ${ }^{1}$ whole core models include both the axial and radial variances in the thermal and irradiation induce stresses as well as the seismic response. The radial thermal and fluence gradients are the largest contributors to strain distortion and stress in the graphite core and thus the main contribution in limiting lifetimes in the core for graphite core components. This report will focus on analyzing the stresses resulting from thermal and fast fluence gradient in the radial direction at the interface of the fuel ring and an outer control rod blocks. Two-dimensional modeling is used to provide sufficient insights that the fast neutron fluence and thermal gradients have on graphite core structural performance before three-dimensional modeling is warranted.

From a mechanical aspect, graphite reflector blocks experience significant stresses resulting from temperature and fast neutron fluence gradients in the radial direction or in the cross-section of the block. These stresses from thermal gradients and irradiation-induced dimensional changes are then further exacerbated by the radial and axial material variation within the billet. Both the temperature and fast neutron gradients in the radial direction in the block are much higher than those in the axial direction, and thus the thermal and irradiation-induced stresses in the axial direction in the block are lower than those from the radial or in-plane direction. Additional stresses of importance are incurred from strains (dimensional and creep) imposed on the graphite as a result of fast neutron irradiation and stresses arising from seismic loads, but these stresses and strains will be addressed in the next revision of the model. Other stresses, such as static loads imposed from the weight of stacked blocks, do not impose significant stresses in the radial direction in the block and are not considered in this analysis. 
The core configuration being considered in this model is published in the General Atomic (GA) Gas Turbine Modular Helium Reactor (GT-MHR) Conceptual Design Description Report, Revision 1, July $1966^{2}$ and is shown in Figure 1. This core contains 102 columns with 10 graphite blocks per column. This configuration was analyzed in an Idaho National Laboratory (INL) Next Generation Nuclear Plant (NGNP) Point Design report ${ }^{3}$ and a conference paper ${ }^{4}$ to determine fast neutron fluxes, gamma heats, compact powers, and fast neutron fluences in the core and reflector. This configuration is assumed to be similar enough to a possible NGNP design that the neutronics from the INL report are used as input for thermal sources.

The pie section of the core noted in Figure 1 is a one-sixth symmetry section of the entire core. An outer reflector block has been chosen to be analyzed using finite elements taking into account the effects on the mechanical and thermal properties from fast neutron fluence and normal operating temperature. The graphite material selected for this analysis is $\mathrm{H}-451$ because established design data exist from previous High Temperature Gas Reactor (HTGR) programs. New nuclear graphites under consideration by the NGNP Program have not been tested or characterized to the extent of H-451 but are currently being developed.

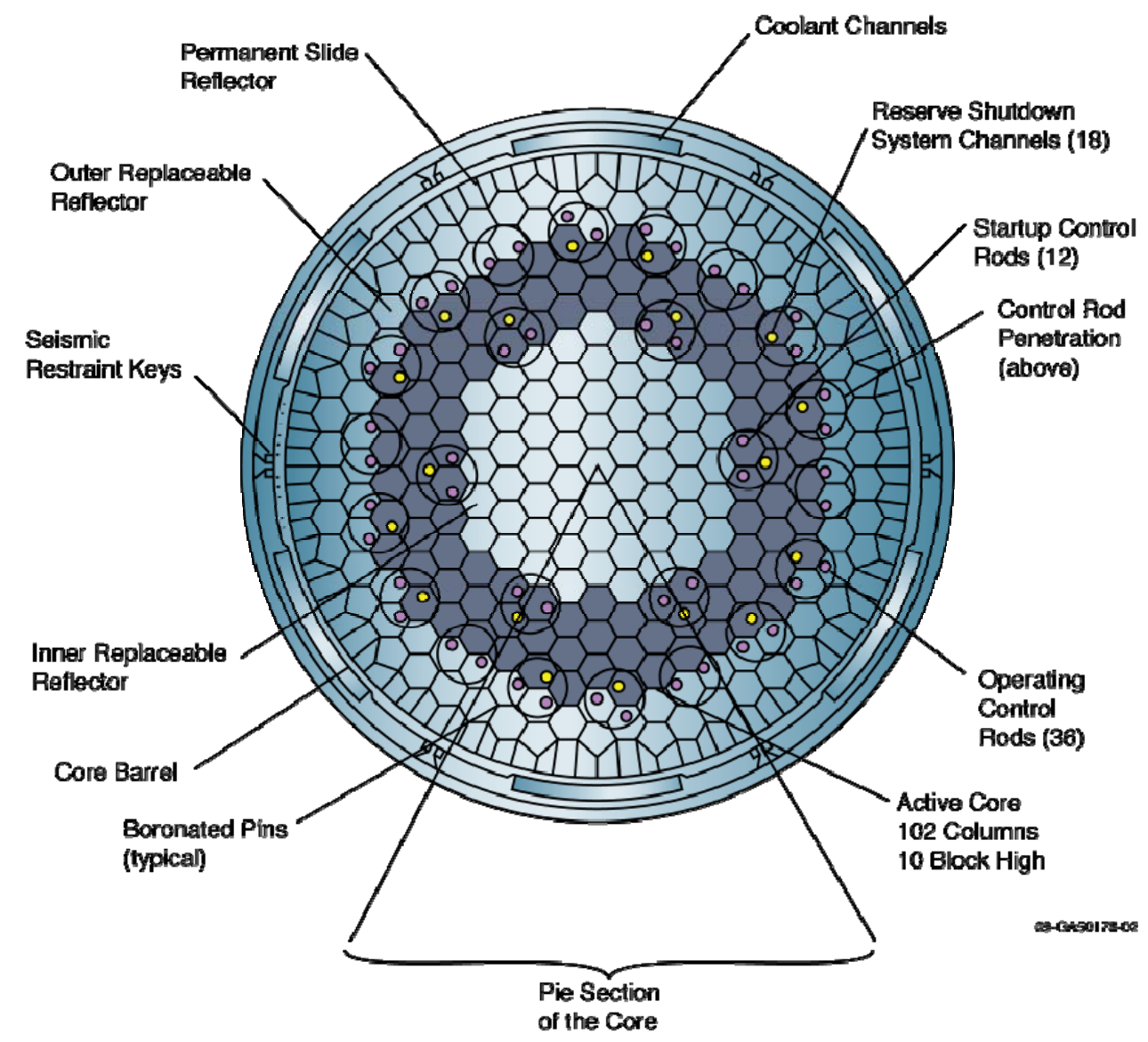

Figure 1. Core configuration of the conceptual design GT-MHR. 


\section{PRISMATIC REFLECTOR BLOCK ANALYSIS}

Figure 2 shows the selected outer reflector control rod block chosen for this assessment. An outer control block was chosen because of the step gradients in temperature and fast fluence the block receives from three adjacent fuel blocks. The location of this reflector block makes it likely to receive a higher dose leading to larger changes in the physical graphite component and its material properties. From experience these outer reflector blocks with control rod channels received a very large dose requiring their replacement after every fueling cycle. ${ }^{1}$ Therefore, choosing these reflector blocks for initial models is a prudent choice.

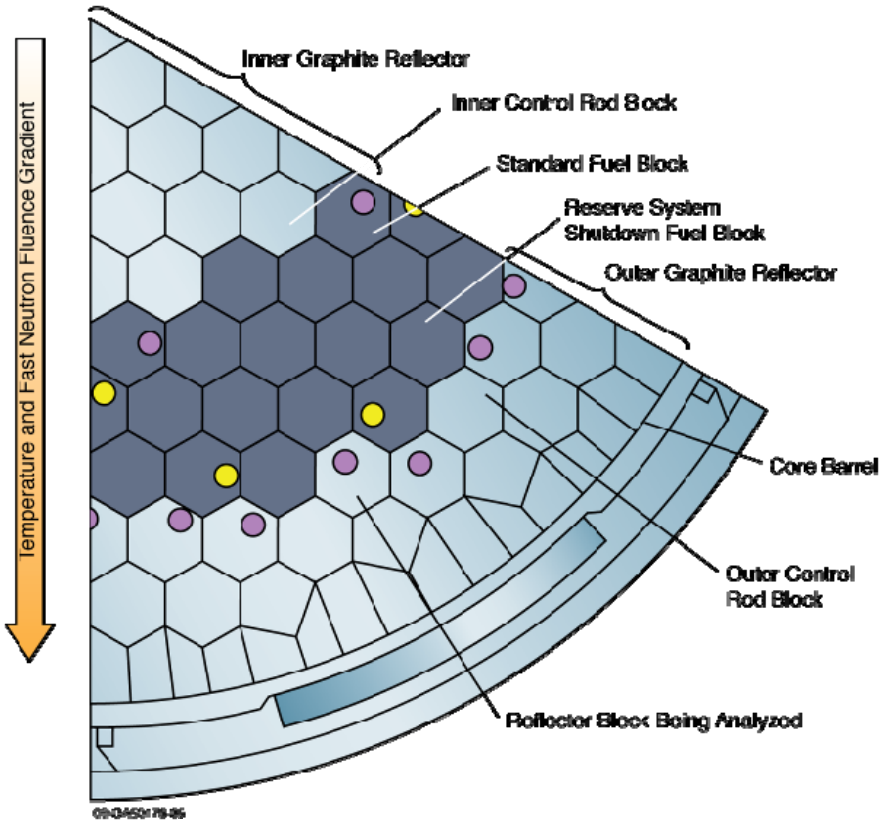

Figure 2. Location of the selected reflector block being analyzed.

The dimensions of the reflector block are shown in Figure 3. The material is assumed to be H-451 with the pertinent material properties of coefficient of thermal expansion, Young's modulus, and thermal conductivity taken from the "Graphite Design Handbook." The Handbook contains the mathematical fits to experimental data collected on billet characterization and irradiation testing from various sources. Mechanical and thermal properties from the Handbook, including irradiation material degradation, will be used as the bases for the mechanical model.

Previous models used separate finite difference thermal analysis codes to analyze the temperature distribution in the graphite, which was correspondingly used as input to early finite element codes that were developed in-house by the vendor. ${ }^{1}$ Nowadays, multiphysic finite element codes, such as the commercially available COMSOL ${ }^{6}$ can solve both the thermohydraulic and structural stress/strain problem simultaneously. 


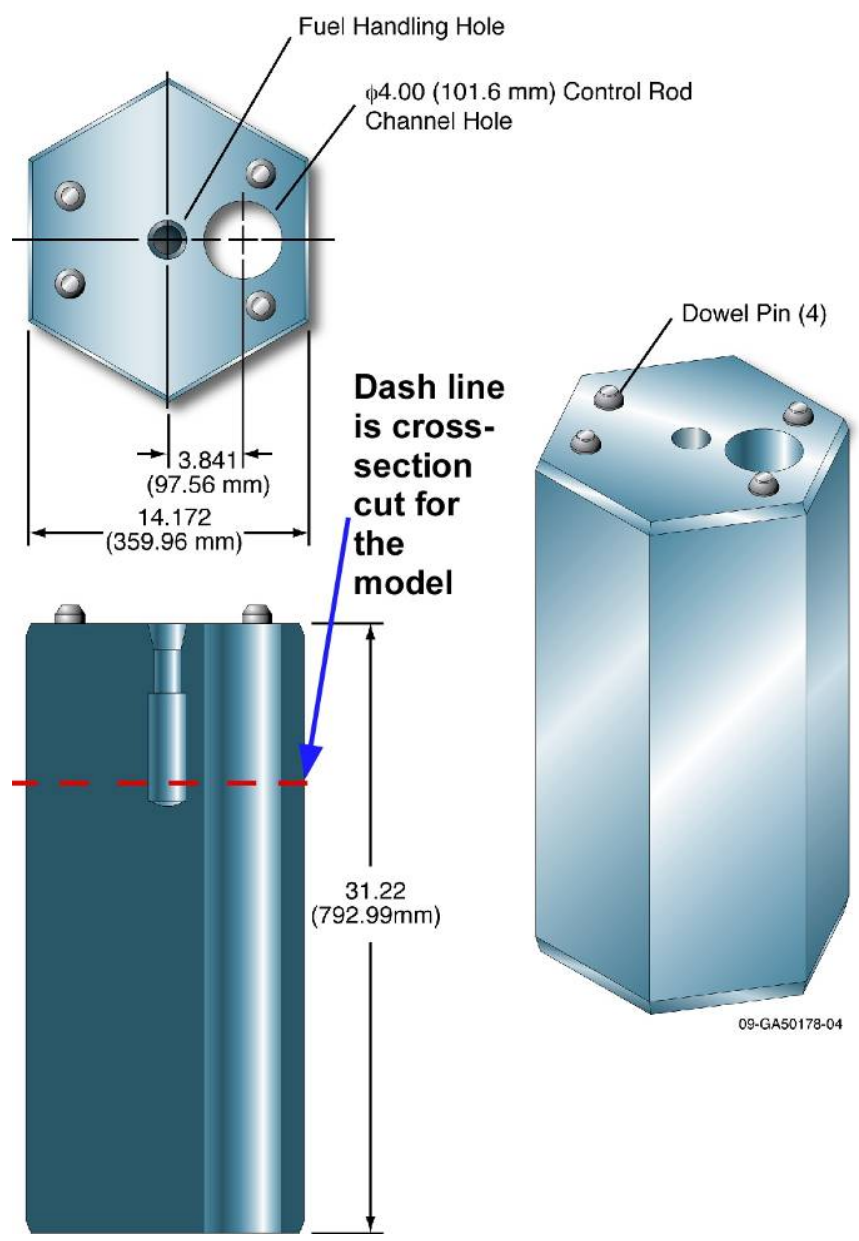

Figure 3. Dimensions of the outer reflector block used in the analysis. Dimensions in inches and millimeters in parentheses. The dotted line in the figure indicates the location of the cross section.

Symmetry allows half of the cross section to be used in COMSOL to build the finite element model using a PC workstation running Windows XP64 Version 5.2 (Build 3790.srv03_sp2_gdr.090310-1024 : Service Pack 2). Figure 4 shows the meshed model of the reflector block. The dowel pins have been excluded for simplicity because no seismic analyses are planed for this model. A cross section of the block is taken at the top of the 3-dimensional block taking into account the fuel handling hole and the control rod channel. The analyzed cross-section geometry assumes no peripheral chamfer is present.

The vertical dimensions of the cross-section range from $+180 \mathrm{~mm}$ at the top core side to $-180 \mathrm{~mm}$ on the bottom reflector side where the origin is taken at the center of the fuel handling hole. The horizontal dimensions range from 0 to $+208 \mathrm{~mm}$ at the midplane of the block. 


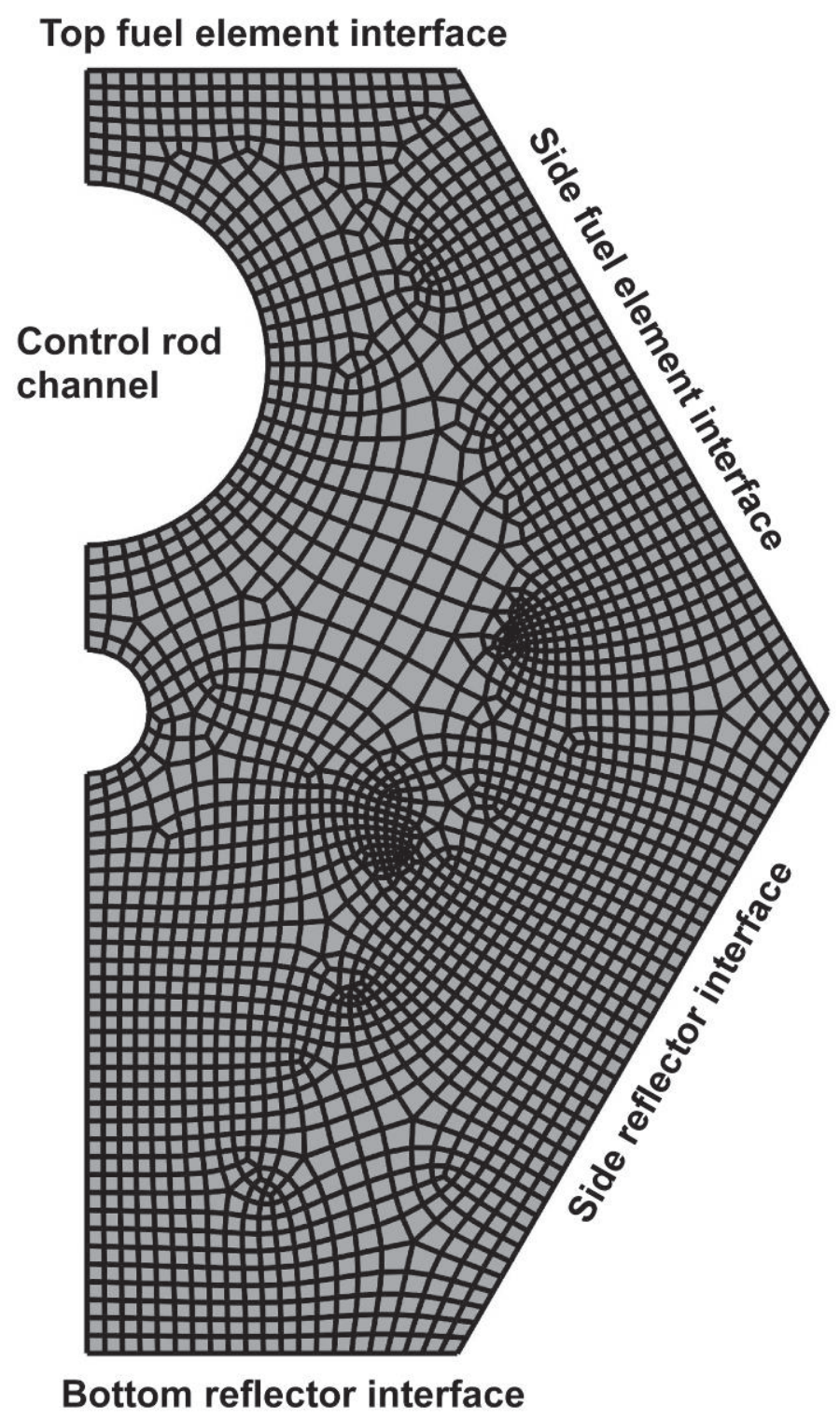

Figure 4. Finite element mesh of the reflector block cross section.

\subsection{Reflector Block Graphite Properties}

Operating conditions for graphite reflector blocks within the historical Ft. St. Vrain prismatic reactor were assumed to be similar to conditions expected in the GT-MHR core design upon which this model is based. Therefore, operating conditions and environment experienced by reflector blocks in the Ft. St. Vrain reactor were used for this initial model. ${ }^{1}$ The Ft. St. Vrain control rod is in a different location in the reflector than the control rod in the conceptual GT-MHR reflector block. Figure 5 shows the temperature and fast neutron fluence per year of reactor operation in a Ft. St. Vrain reflector block as a function of distance between the two faces in Figure 4. The block temperature profile was obtained without taking into account the dependence of thermal conductivity on local neutron fluence. The model assumes only a radial temperature and fluence profile. ${ }^{1}$ It does not take into account that other reflector blocks have adjacent fuel blocks on three sides, which would tend to interact with each other and 
significantly complicate the temperature and fluence profiles through the reflector block. The model assumes that the fast fluence decays by a factor of two in 2.7 inches of graphite. ${ }^{1}$ The radial exponential decay of the fast fluence in the in-plane can then be calculated similar to a radioactive decay profile. From Figure 5, the exponential decay of fast fluence has resulted in a several orders of magnitude decrease in fast fluence at the bottom side of the reflector cross section.
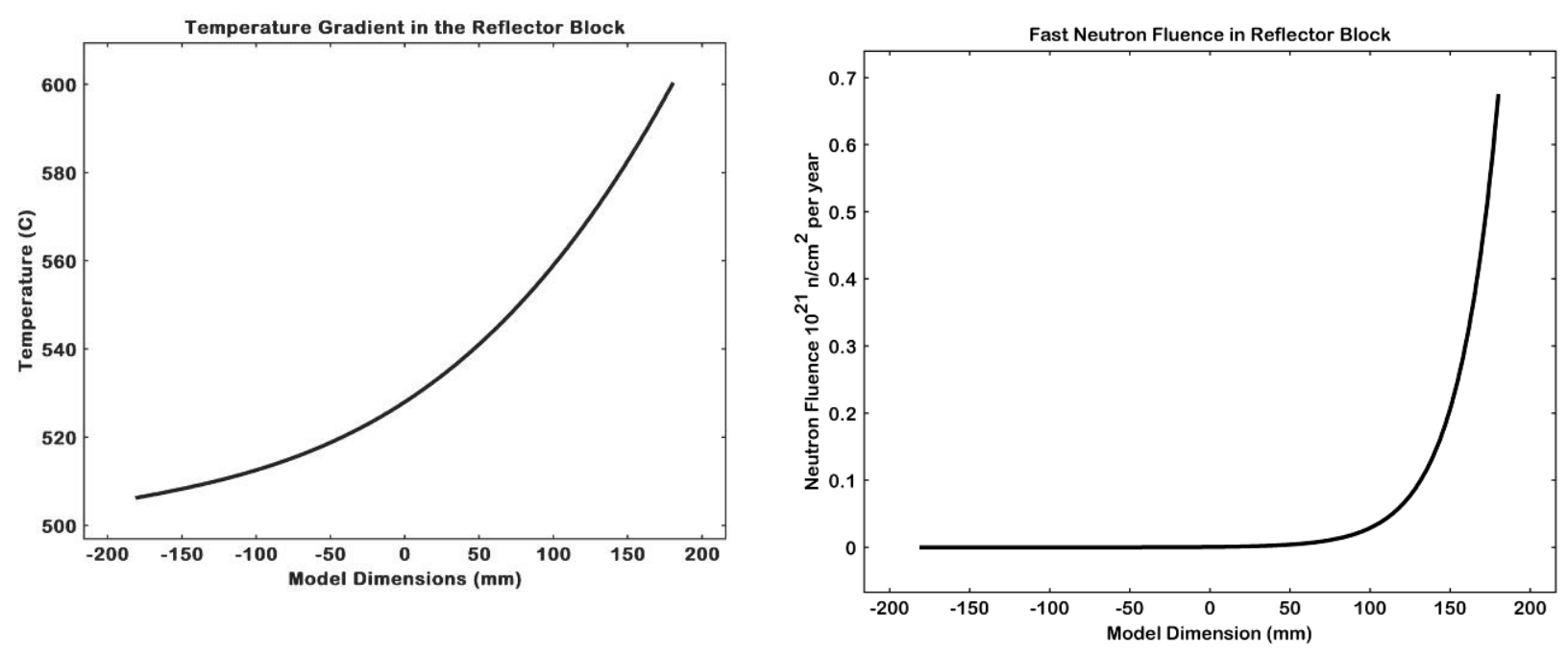

Figure 5. Temperature and fast neutron fluence through the reflector block. The reflector/core interface is at $180 \mathrm{~mm}$.

As an initial look at the thermal stresses in the reflector block, the temperature profile similar to the plot in Figure 5 will be used taking into account the local materials properties dependence on fast fluence. ${ }^{5}$ The exponential decay profile for the fluence gradient through the reflector block cross section will be used in the model. ${ }^{1}$ Figure 6 is a plot of the variance of $\mathrm{H}-451$ thermal expansion in the axial direction with temperature and neutron fluence. ${ }^{5}$ The thermal expansion in the radial direction is of slightly larger magnitude, but the same variance on temperature and neutron fluence. The reference temperature of the thermal expansion fit is $500^{\circ} \mathrm{C}$. 


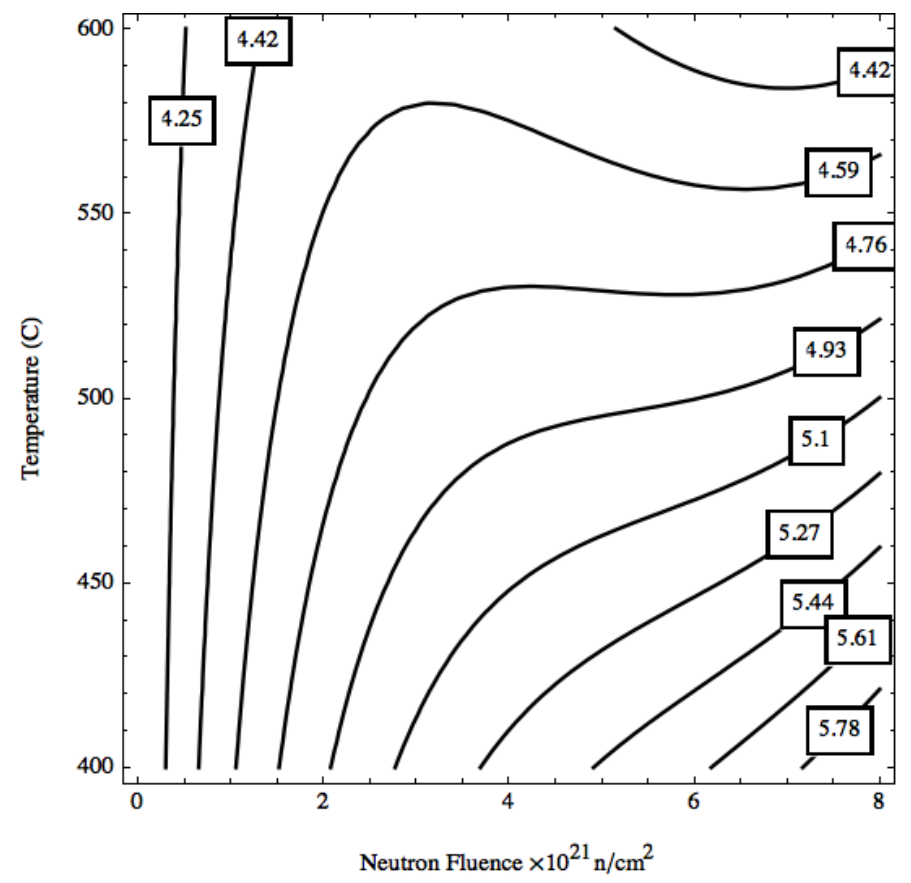

Figure 6. H-451 thermal expansion in the axial direction as a function of irradiation temperature and neutron fluence. Thermal expansion is in units of $10^{-6} /{ }^{\circ} \mathrm{C}$.

For H-451, Young's modulus in the radial and axial directions varies as a function of the density within the cylindrical graphite billet. The hexagonal block is machined from the cylindrical graphite billet. Figure 7 is a contour plot of the radial Young's modulus varying from the mid-height of the billet. ${ }^{5}$ To gain insight into the effects of radially varying Young's modulus in the cross section of the model, an assumed height of zero is used in Figure 7 to obtain Young's modulus as a function of the billet radius. This radius is calculated from the center of the cross section in the model. In addition, Young's modulus will vary with locally accumulated fast neutron fluence. The fluence-dependent modulus will be implemented in the future when the creep model is added in future versions. The creep model will be discussed later in the report. 


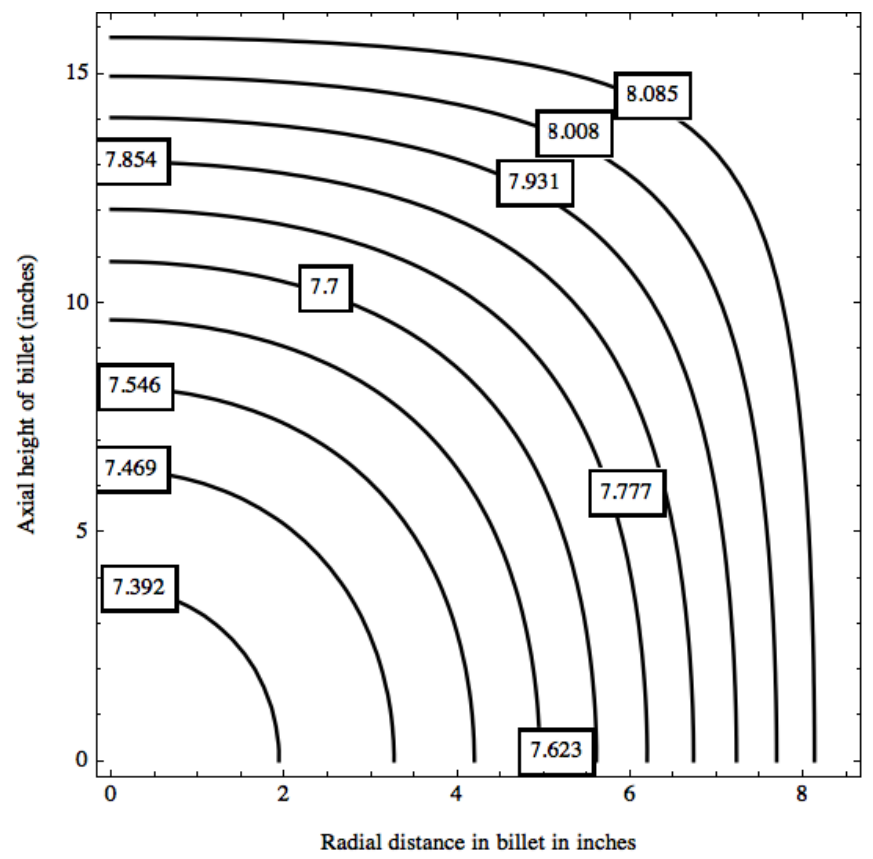

Figure 7. H-451 radial Young's modulus as a function of radial and axial distance in the billet taken from the midplane of the billet. Numbers in boxes are in GPa.

Figures 8 and 9 are the COMSOL model results for total displacement in the reflector block at 1 and 5 years. The temperature distribution was held constant for these two runs but the coefficient of thermal expansion and thermal changed as function of fluence.

Figures 8 and 9 used temperature and fluence profiles that assumed a single heat and fast fluence source from the fuel cross section surrounding the reflector block as was done in Reference 1 . Figure 12 shows the reflector block being analyzed as being surrounded by three fuel blocks requiring a further development of heat and fast fluence sources other than a single source. The next section will develop the necessary heat and fast fluence sources to support the structural assessment of the reflector block. 


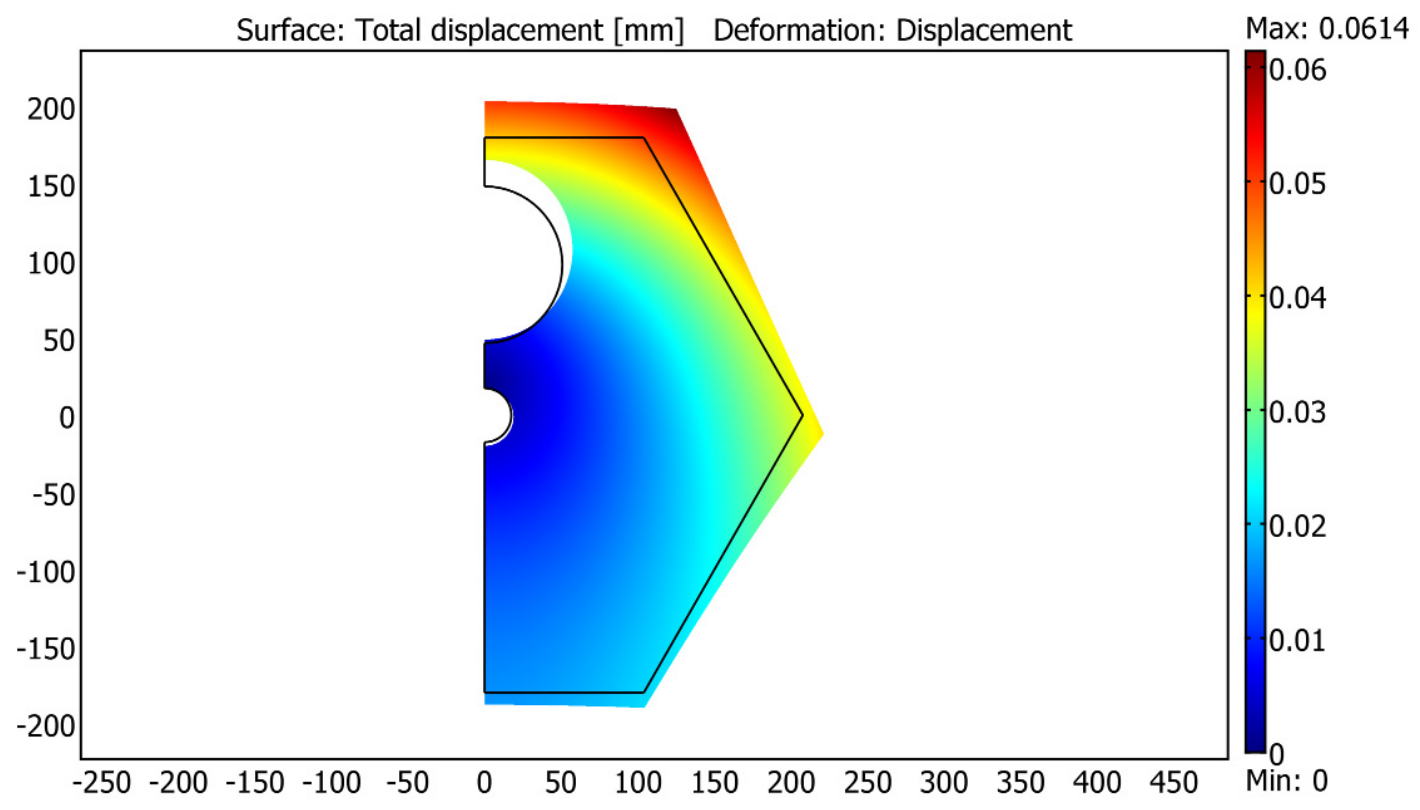

Figure 8. Total displacements at 1 year of operation. The solid black line is the original shape of the reflector block. The displacements have been artificially scaled upward to aid in viewing the deformations. The displacements are in millimeters.

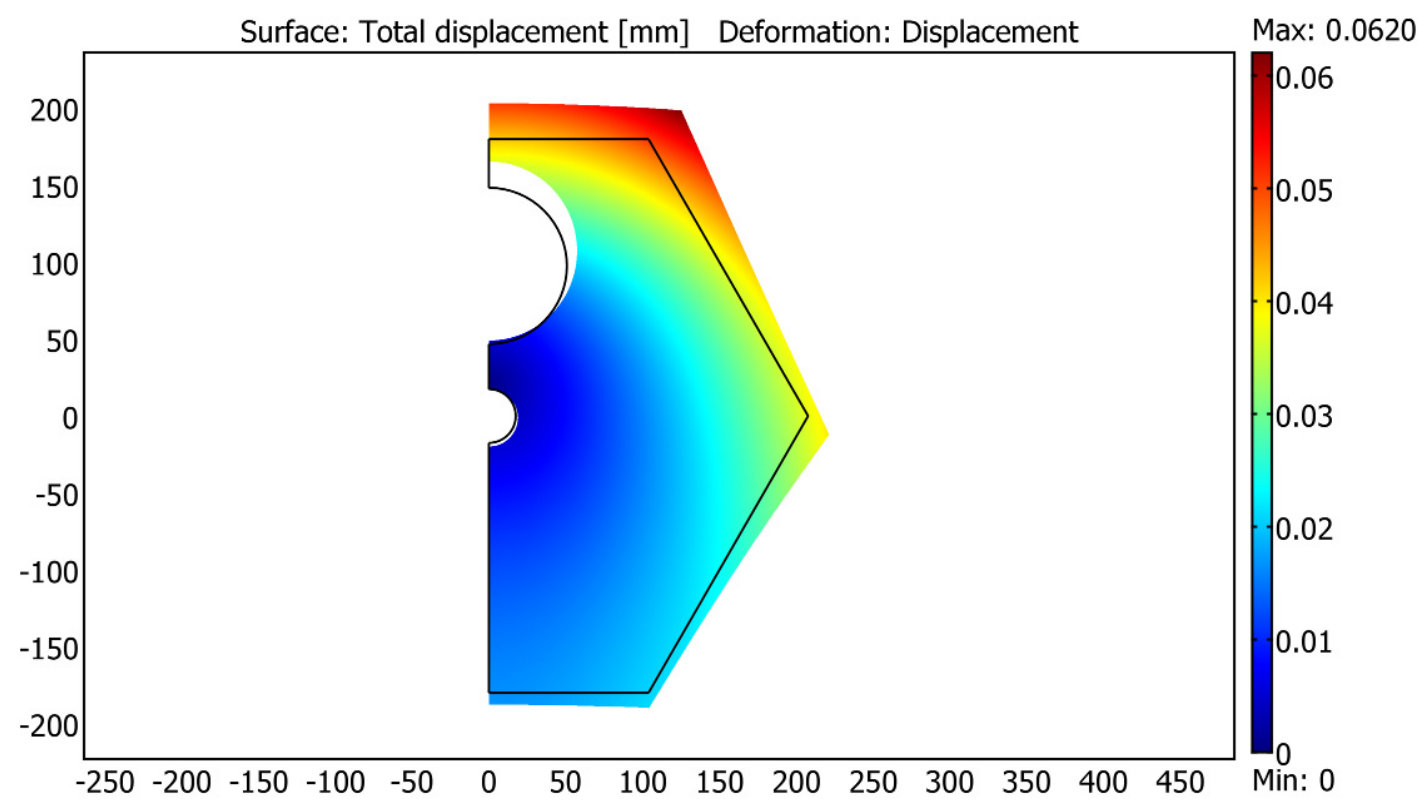

Figure 9. Total displacements at 5 years of operation. The solid black line is the original shape of the reflector block. The displacements have been artificially scaled upward to aid in viewing the deformations. The displacements are in millimeters. 


\subsection{Temperature Analysis in the Reflector Block}

The prior model in Section 2.1 requires different assumptions to take into account the local fluence dependent material properties. The temperature profile and radial fluence gradient used in the prior model must be replaced with temperature conditions on the reflector cross-section periphery that corresponds to temperatures from a similar cross-section model of the adjacent fuel blocks. Fast neutron fluence from these fuel model cross sections must also be considered. These boundary conditions will represent a closer approximation to the actual conditions seen by the reflector block in a Very High Temperature Reactor (VHTR) core.

Reference 3 provided fast average neutron fluences at the fuel and reflector block interface for a $600 \mathrm{MWt}$ NGNP design with a $1,000^{\circ} \mathrm{C}$ outlet temperature. The fast fluence profile is apportioned in the reflector cross-section model with fluence entering from both faces adjacent to the fuel. This is only an assumption in lieu of the actual neutron flux mapping that could be calculated with a more sophisticated neutronic analysis. Figures $10 \mathrm{a}, 10 \mathrm{~b}$, and $10 \mathrm{c}$ illustrate the fluence contribution from the adjacent fuel elements in the reflector block cross-section model.

The gamma heating in the block is taken as an internal heat source and the heat distribution is assumed to be radial only. ${ }^{3}$ The contribution from the gamma heat is assumed to be small compared to the transmitted heat flux from the fuel blocks. Figure 11 shows the gamma heat distribution in the reflector block. 


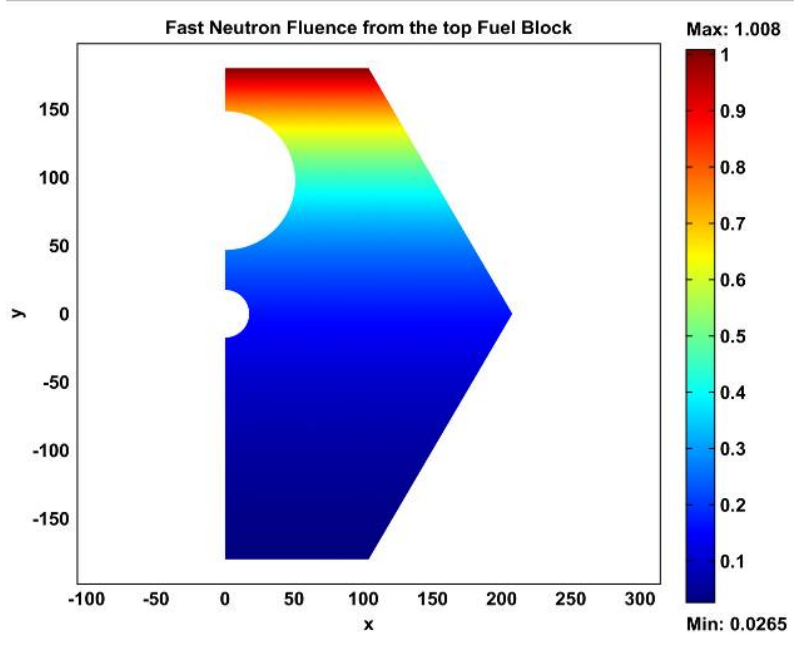

a

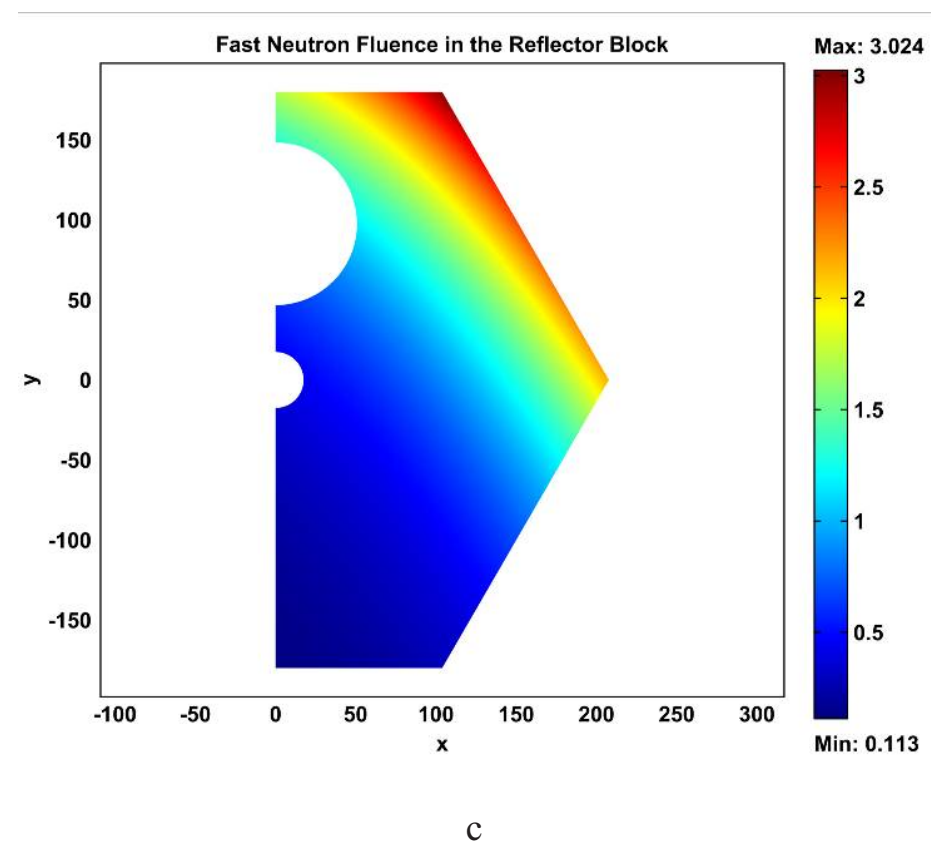

c

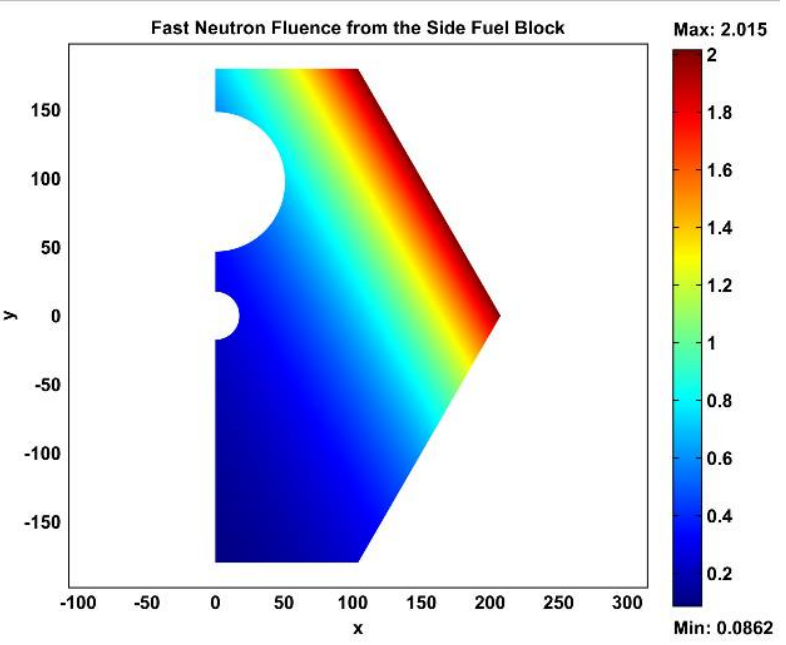

b

Figure 10. a,b,c. Fast neutron fluence from the top and side fuel block crossing the perimeter at 6 years of operation. $\mathrm{X}$ and $\mathrm{Y}$ are spatial dimensions of the reflector block in millimeters. The fluence has units of $10^{21} \mathrm{n} / \mathrm{cm}^{2}$. 


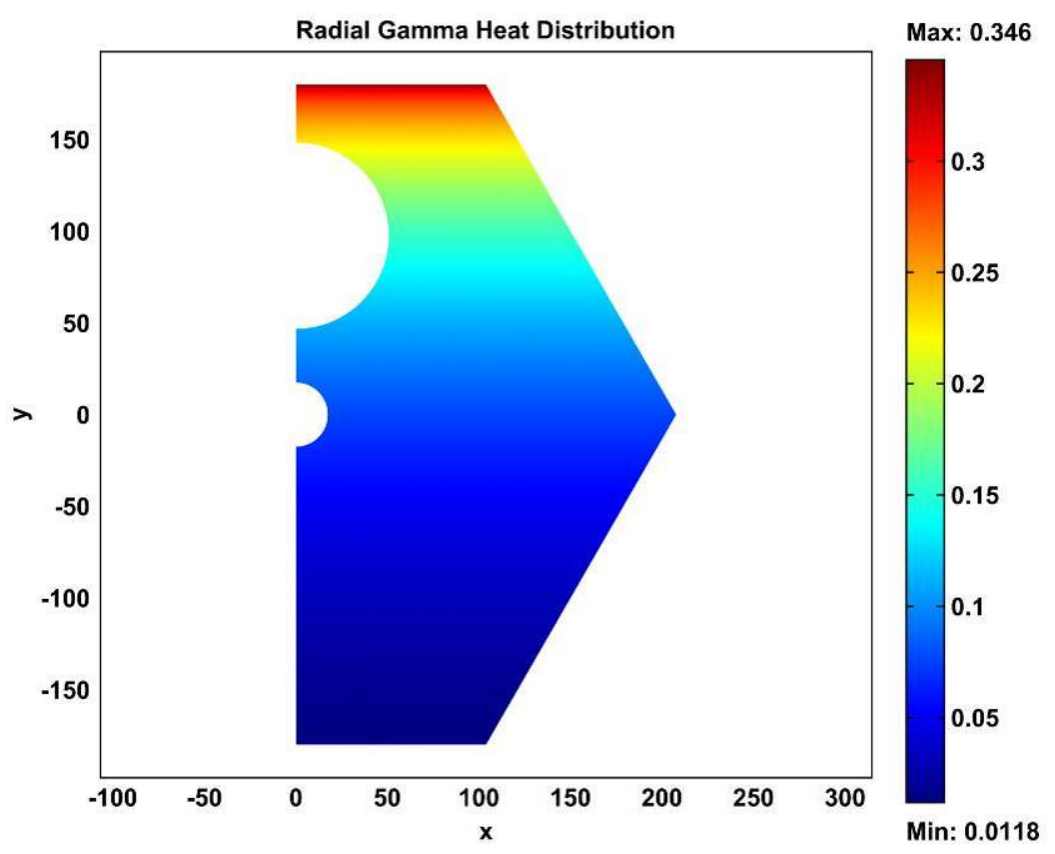

Figure 11. Gamma heat distribution in the reflector block. X and Y are spatial dimensions of the reflector block in millimeters. Gamma heat is in units of $\mathrm{W} / \mathrm{cm}^{3}$.

Knowing the correct heat gradient on the reflector block model's cross-section boundaries will assist in predicting temperature profiles in the cross section that in turn affects graphite material properties in the reflector cross section. Figure 12 shows the reflector block cross section receiving heat flux from three fuel elements. Assuming only radial heat flow and no azimuthal heat flow around the core, the heat sinks for the core must be the convective heat transfer of the helium coolant. The second assumption is that the heat energy not absorbed by the helium coolant will be conducted radially out to the inner and outer reflectors in the plane of the cross section.

A model of a fuel element and the bypass flow heat conductance assumptions around the fuel element are required to examine the heat flux or temperature at the interface between the upper fuel element and outer reflector. Figure 13 shows the dimensions of a typical prismatic fuel element used in the GT-MHR and NGNP designs. A more prudent choice of model is the one-twelfth sector cross-section model of the fuel element. Figure 14 shows the one-twelfth sector cross-section fuel element model and the mesh used to analyze heat transfer within the model. A distribution of smaller elements was placed at the boundary interface between the fuel and reflector cross-section models to assist in the prediction of the heat flux. The alignment dowels are not modeled because no seismic movement is present.

Thermal boundary condition on the cross-section model consists of adiabatic boundaries on the fuel element graphite cross-section boundaries. The fuel compacts are assumed to have a power density and no gap resistance between the compacts and graphite. The helium coolant holes have heat transfer coefficient applied at the perimeter with a constant helium gas temperature in the hole. A small heat transfer coefficient (approximately three orders of magnitude smaller compared to the heat transfer coefficient of the coolant hole) is applied to the graphite boundary between the fuel element and reflector. This boundary condition represents the heat extracted by the bypass flow between fuel elements. The thermal conductivity of the graphite and fuel compacts were assumed to be the same. The thermal conductivity employed an empirical relationship that accounted for the local temperature and fast fluence in estimating its value. These same conditions were employed in a SMiRT-18 conference paper by Lejeail and 
Cabrillat $^{7}$ using a design $600 \mathrm{MWt}$ and a $1030^{\circ} \mathrm{C}$ prismatic to investigate the thermal and structural response of a one-twelfth fuel element cross section.

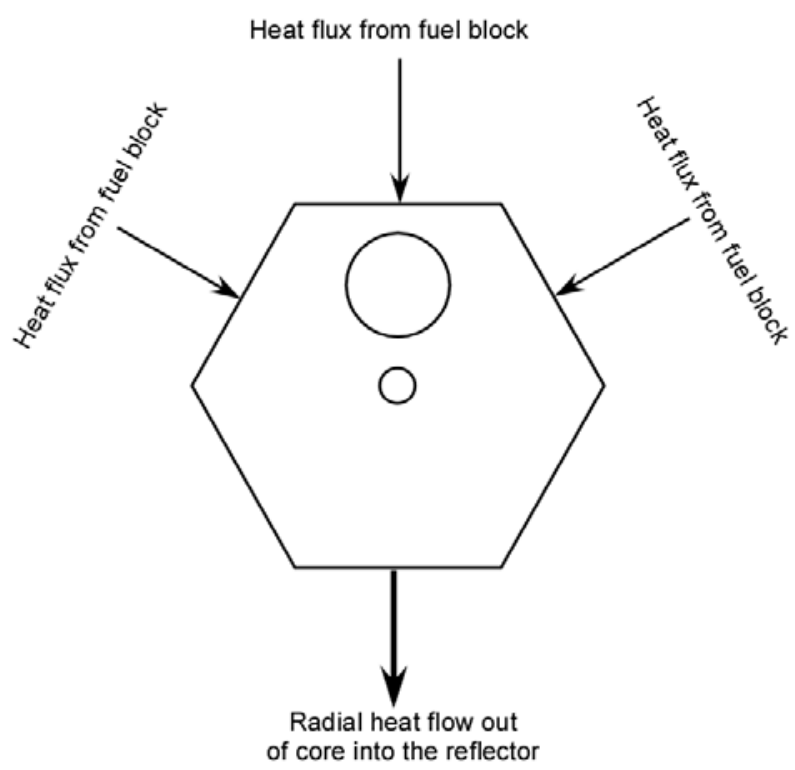

Figure 12. Heat sources for the prismatic reflector block cross section being examined. 


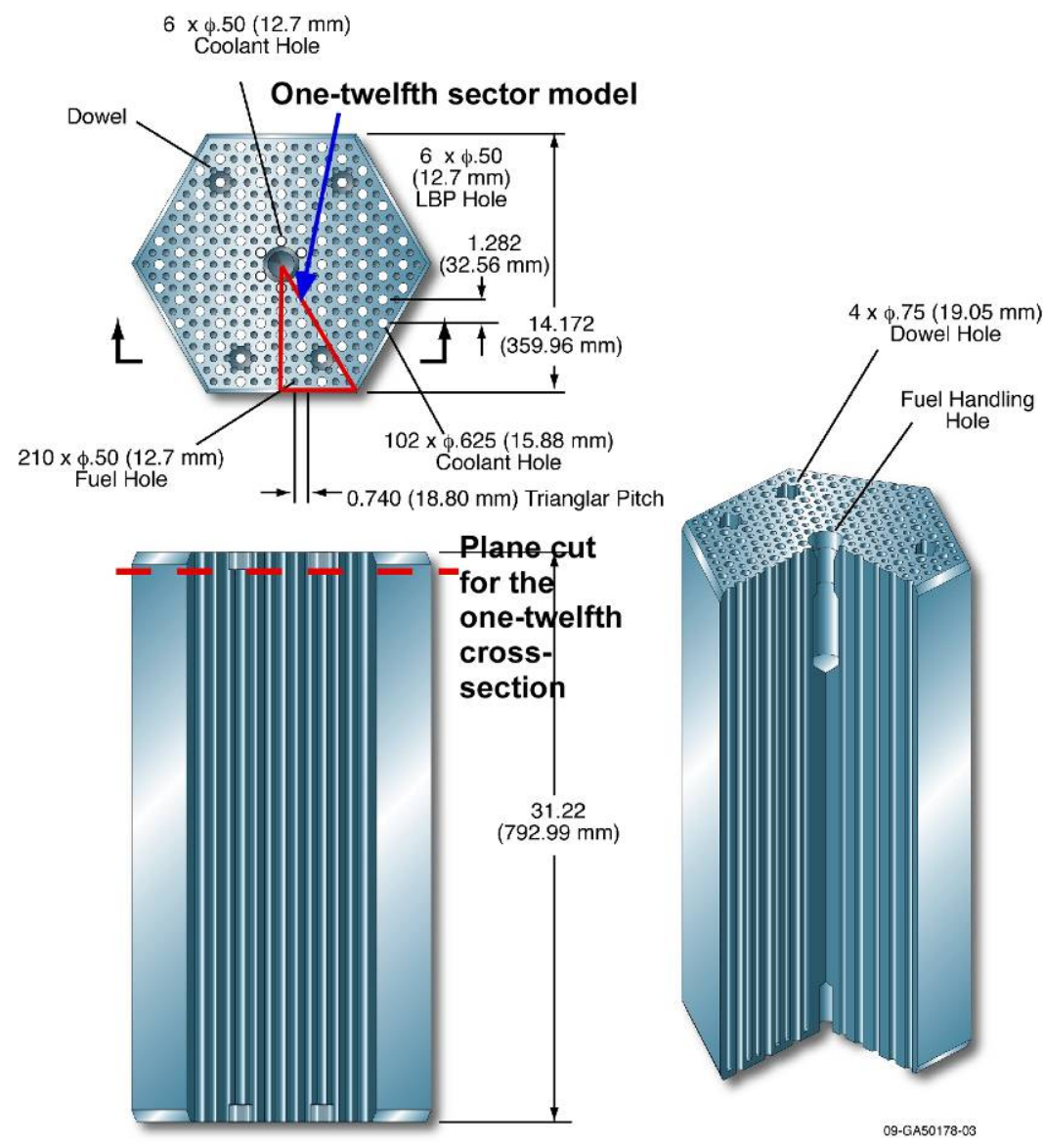

Figure 13. Prismatic fuel element with one-twelfth sector cross section superimposed. Dimensions are in inches with millimeters in parentheses. 


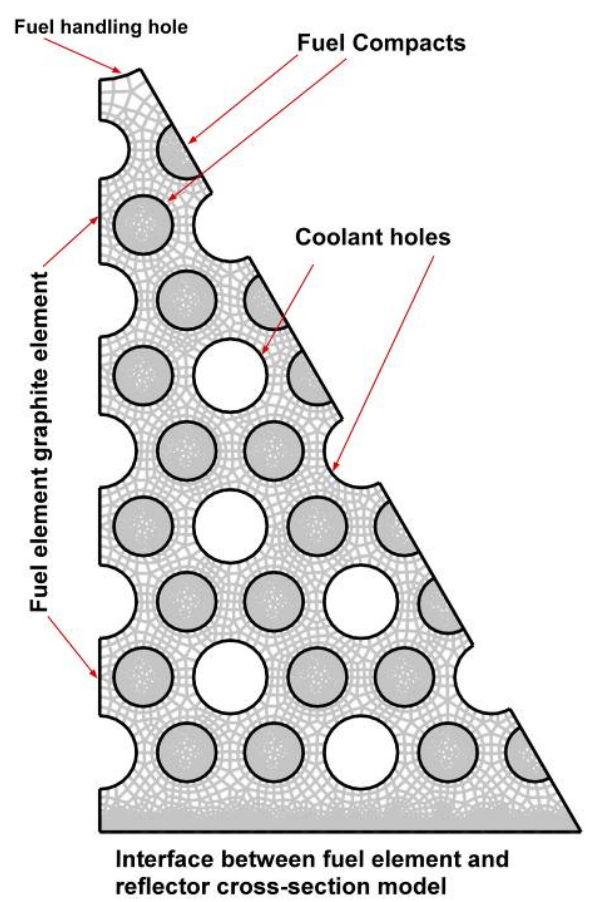

Figure 14. One-twelfth sector cross-section model.

Figure 15 shows the results of the heat transfer in the graphite material for the one-twelfth sector cross section. The temperatures in the graphite are slightly higher than predicted due to differences in the coolant hole diameter around the fuel handling hole. ${ }^{7}$

The pattern of heat distribution in the graphite in Figure 15 is the same as seen in Reference 7. The high temperature in the lower right hand corner is the location of power peaking in the apex of the hexagon. It is at this location where compacts with burnable poisons have been located in prior fuel elements to reduce the temperature peaking in the hexagon apexes. The choice of employing burnable poisons compacts at the apexes and elsewhere in the fuel block will depend on the reactor vendor's design. 


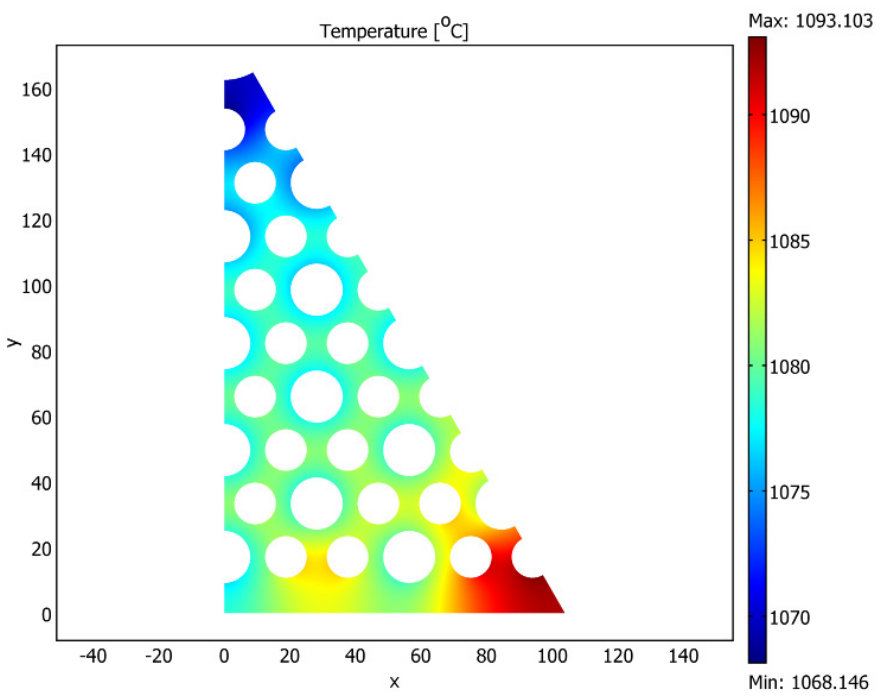

Figure 15. Graphite temperature in the one-twelfth sector cross-section model. X and $\mathrm{Y}$ are the spatial dimensions of the model in millimeters

Figure 16 shows the entire one-twelfth sector cross section including the fuel compacts temperatures.

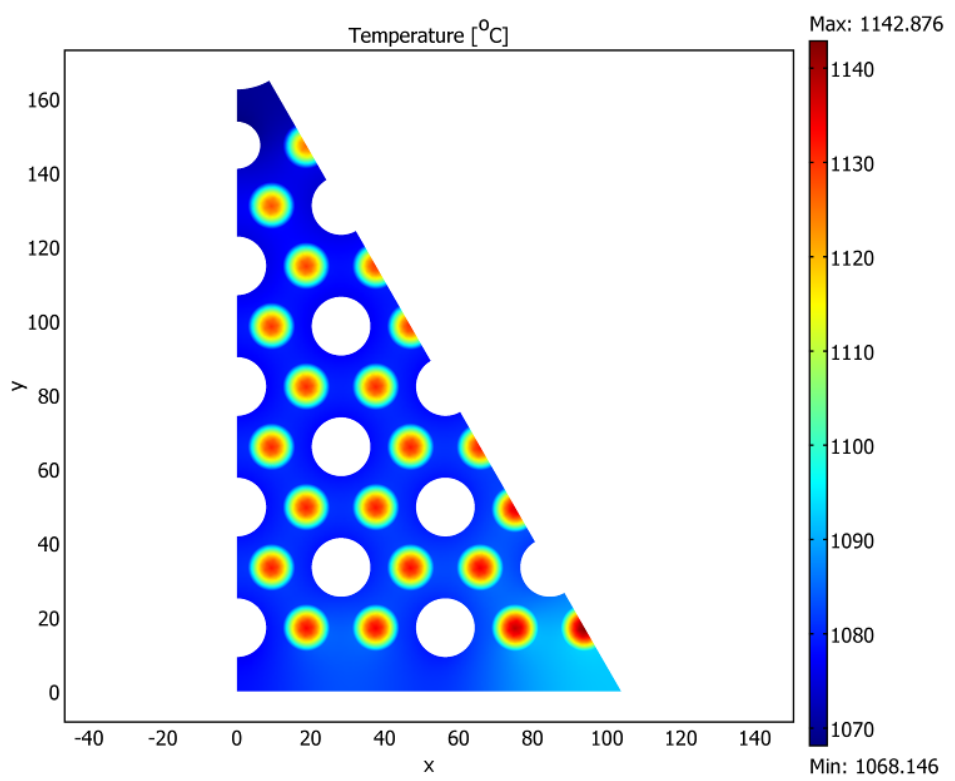

Figure 16. One-twelfth fuel sector cross section showing temperatures of fuel and graphite. $\mathrm{X}$ and $\mathrm{Y}$ are spatial dimensions of the model in millimeters.

Figure 17 plots the heat flux at the bottom of the one-twelfth fuel sector cross section. Positive heat flux is heat crossing the boundary, and negative heat flux is heat entering the boundary. The negative heat flux is due to the two large coolant holes near the boundary, which is due to their high heat transfer to the helium coolant, thus creating a strong local heat sink. The positive peaks correspond to the outward heat gradient created by the double pair of fuel compacts. 


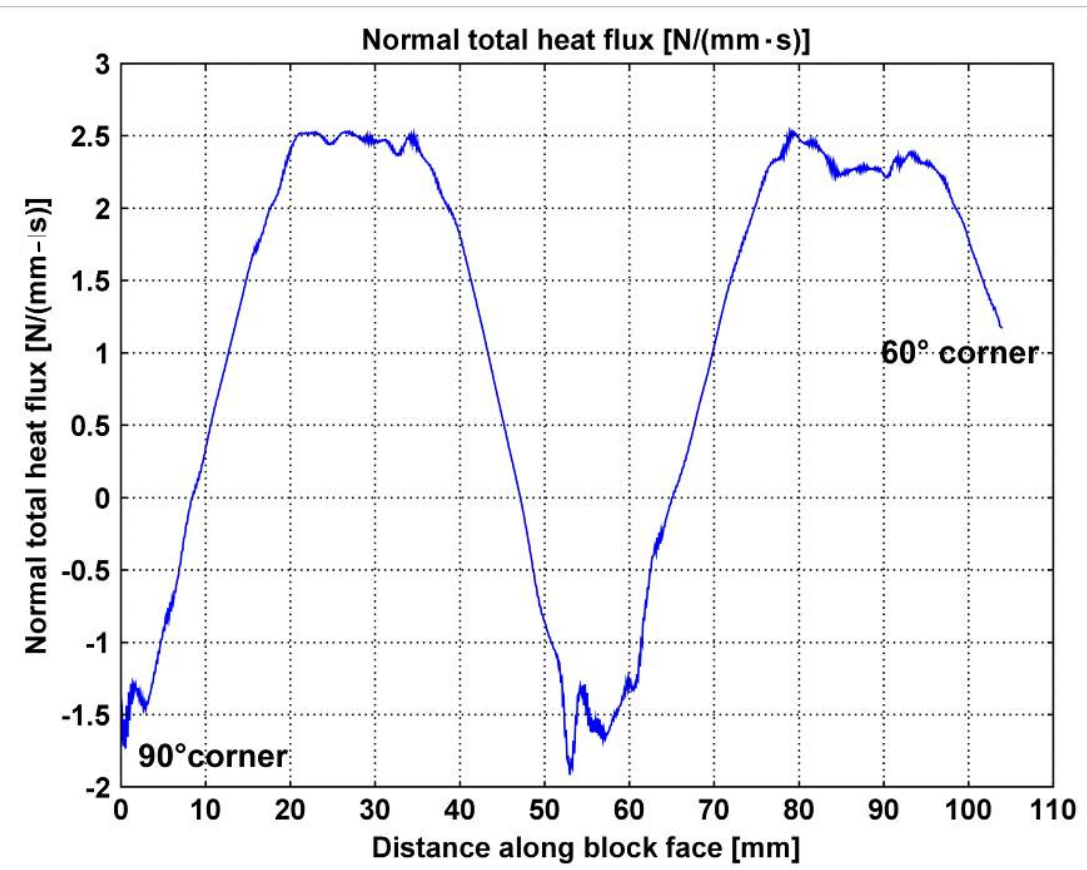

Figure 17. Plot of heat flux leaving and entering the lower boundary of the one-twelfth fuel sector cross section.

The one-twelfth sector cross section means this model is repeated twelve times to form in-place cross section of the fuel element. There is a need to determine if the one-twelfth fuel sector cross-section model provides a representative model to determine the actual heat flux that would be transported by conduction to the adjacent reflector cross section. To answer this question, a half fuel element cross section was constructed using the same heat sources and sinks used in the one-twelfth fuel sector cross section. Two assumptions are imposed on the boundary conditions on the half fuel element cross section. The first assumption is the heat sink for the core must use convective heat transfer of the helium coolant gas and conduction to the inner and outer reflector with no azimuthal temperature gradients. An adiabatic boundary condition is then imposed on the peripheral cross-section boundaries except on the face adjacent to the reflector interface. Residual heat not removed by convective heat transfer is conducted in-plane to the interface of the fuel element and the reflector. At the interface, a small amount of heat is removed by bypass flow. To simulate the bypass conductance at the interface, a small heat transfer coefficient is placed on the face adjacent to the interface instead of an adiabatic condition. The sink temperature at the interface was assumed to be helium gas at the same temperature in half fuel element cross section. This represents the heat transported by the bypass flow between the graphite blocks in the core. The temperature on the face fuel element cross section is then imposed on the face of the reflector cross-section interface.

Below is a list of thermal/material parameters that can be used to perform sensitivity analysis to determine if the heat flux or fuel block perimeter temperature varies with changes in the parameters:

- Compact power density

- Coolant heat transfer coefficient

- Coolant temperature

- Bypass conductance heat transfer coefficient 
- Temperature and fluence-dependent graphite thermal conductivity

- Temperature and fluence-dependent coefficient of thermal expansion.

The last three parameters are also affected significantly by irradiation dimensional changes and neutron creep strains. Sensitivity analysis will be possible after graphite material models for irradiation dimensional change and neutron creep have been added to the finite element model.

Figure 18 shows the half fuel element cross section, which is modeled using finite elements. Using symmetry, only half of the cross section is required to be modeled. The mesh employed is not shown due to the density of elements adequately needed to represent the model. The internal radial lines in the figure are internal lines of symmetry in the model.

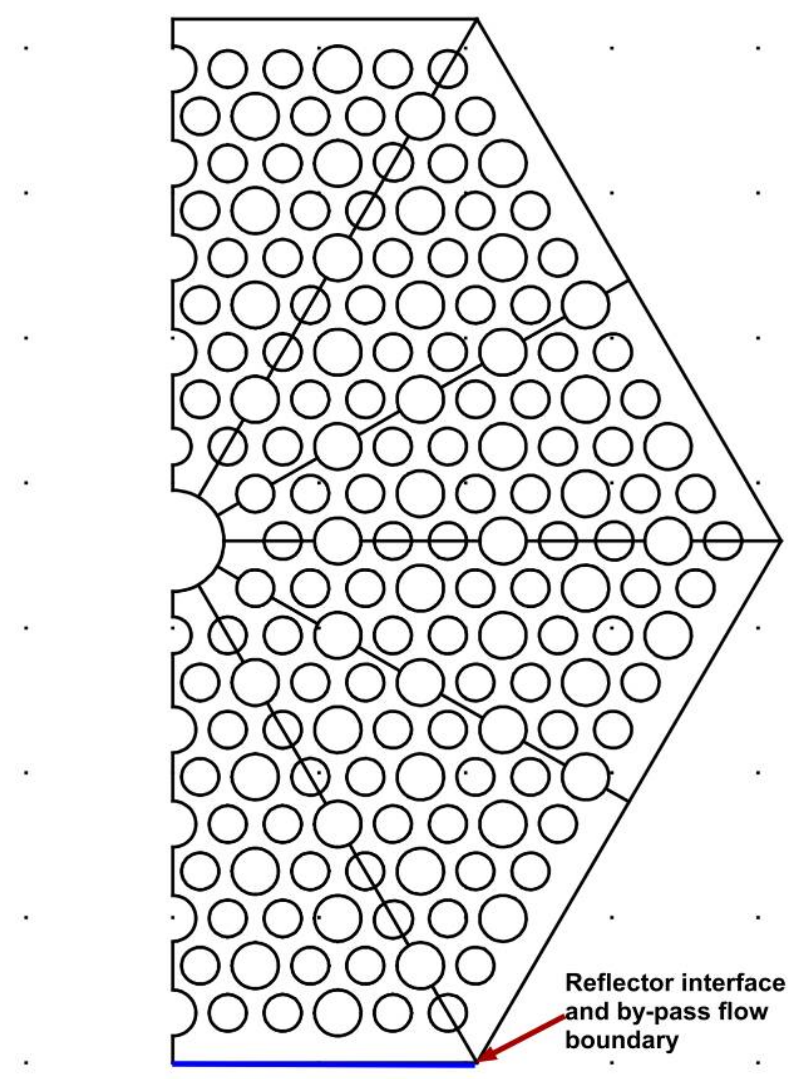

Figure 18. Model of a half fuel element cross section. Only half of the fuel element is modeled due to symmetry.

Figure 19 shows the temperature distribution in the fuel element cross section for the applied boundary conditions discussed previously. The higher temperature regions are the fuel compacts. 


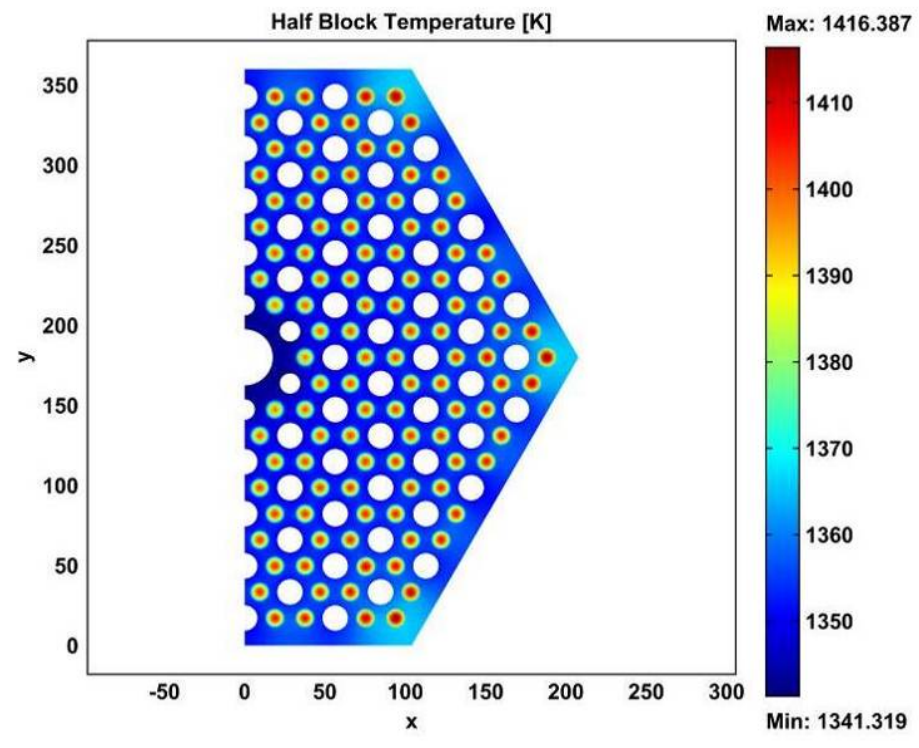

Figure 19. Temperature in the half fuel element cross-section model. Peak compact fuel temperatures are $1,416 \mathrm{~K} . \mathrm{X}$ and $\mathrm{Y}$ are the spatial dimensions of the model in millimeters.

Figure 20 illustrates just the graphite temperature without the fuel compacts. No evidence of temperature gradients is available in the cross section; thus the heat being generated is removed by the helium coolant because of the prescribed heat transfer coefficient and coolant gas temperature. No residual heat transfers to the interface with the reflector; nevertheless, there is still a heat flux on the outer face at the interface due to the bypass flow. Figures $21 \mathrm{a}$ and $21 \mathrm{~b}$ show temperatures and heat fluxes on the outer perimeter of the fuel element cross section. Figure 21a starts at the interface between the fuel element and reflector at the 90-degree corner of the cross section and proceeds counterclockwise to the top face to the plane of symmetry (90-degree corner). The three large peaks in the temperature plot correspond to the peak temperatures in the hexagonal apexes of the graphite block because of the three fuel compacts in the vicinity of each corner. The lower peaks occur at the coolant holes that are adjacent to the outer perimeter of the cross section. Figure $21 \mathrm{~b}$ shows heat flux on the perimeter of the fuel element cross section. The two higher peaks are the heat flux on the lower face of the cross section. 


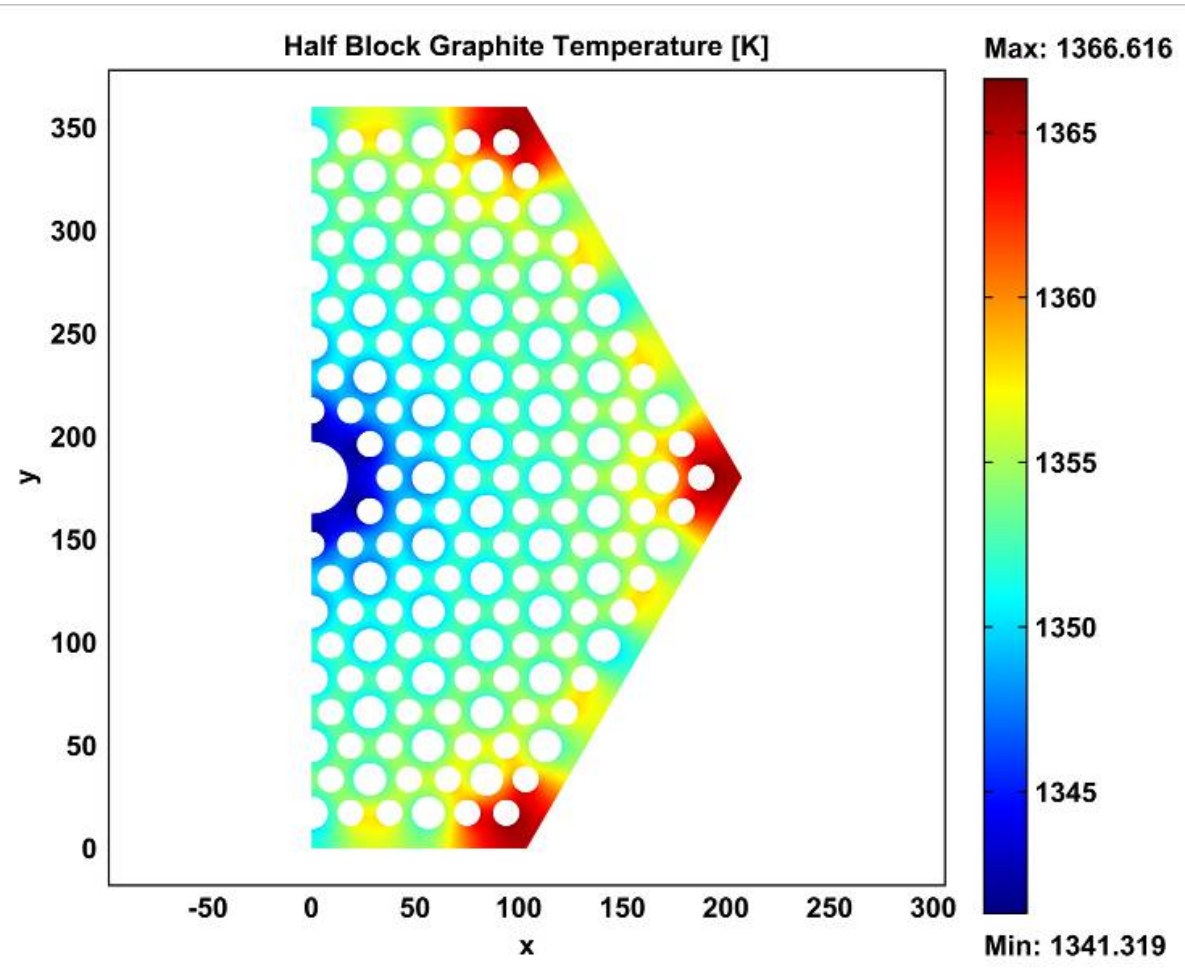

Figure 20. Graphite temperature distribution in the fuel element cross section. The fuel compacts are not included in this figure. $\mathrm{X}$ and $\mathrm{Y}$ are the spatial dimensions of the model in millimeters

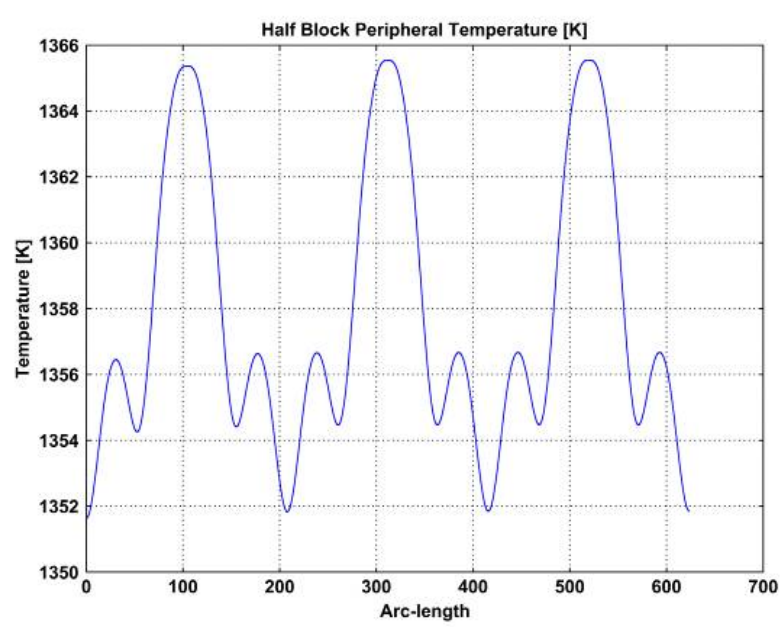

a

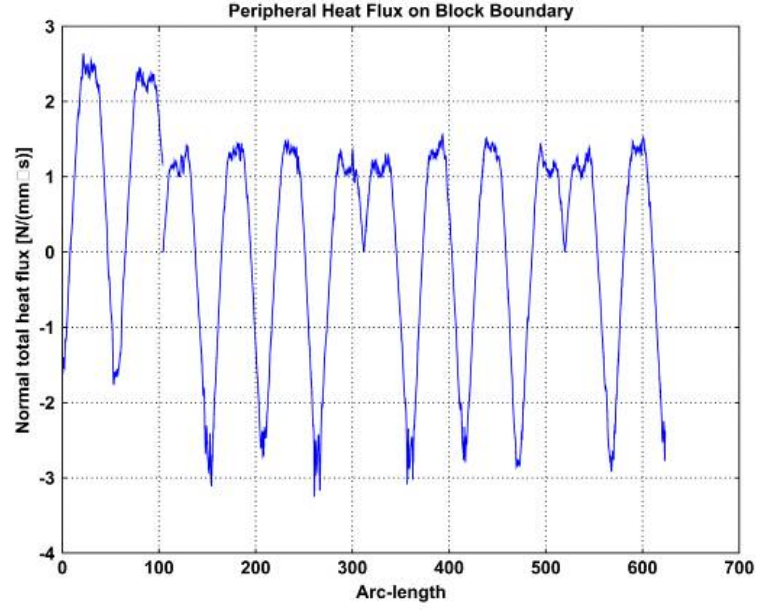

b

Figure $21 \mathrm{a}$ and $\mathrm{b}$. Fuel element cross-section perimeter temperature and heat flux. The plot starts at the interface between the fuel element and reflector at the 90-degree corner and proceeds counterclockwise around the perimeter (arc-length) in millimeters. 
Using Figure 21a, the face temperature on the fuel element cross section at the interface between the fuel element and reflector is set to the reflector cross-section perimeter temperature at the faces adjacent to fuel elements. A small temperature drop will occur across the gap at the interface, but as a first approximation the temperature will be bounding. Figures 22a, b, and c present the peripheral boundary temperatures for the reflector cross-section model. Figure 22a is the temperature on the reflector cross-section faces adjacent to the fuel elements. The plot starts at the 90-degree corner at the interface and proceeds clockwise to the horizontal midplane at the right most apex of the reflector cross section. Figure $22 \mathrm{~b}$ starts at the opposite interface with the remaining reflectors at the 90 -degree corner and proceeds counter clockwise to the right most apex of the reflector block. The temperature at the bottom interface with the reflector is assumed to be $773 \mathrm{~K}$, and a linear temperature gradient between the lower face and the horizontal midplane is assumed to exist on the block peripheral boundary. Figure $22 \mathrm{c}$ is the entire peripheral boundary temperature from the bottom reflector interface to the fuel element interface proceeding counterclockwise.

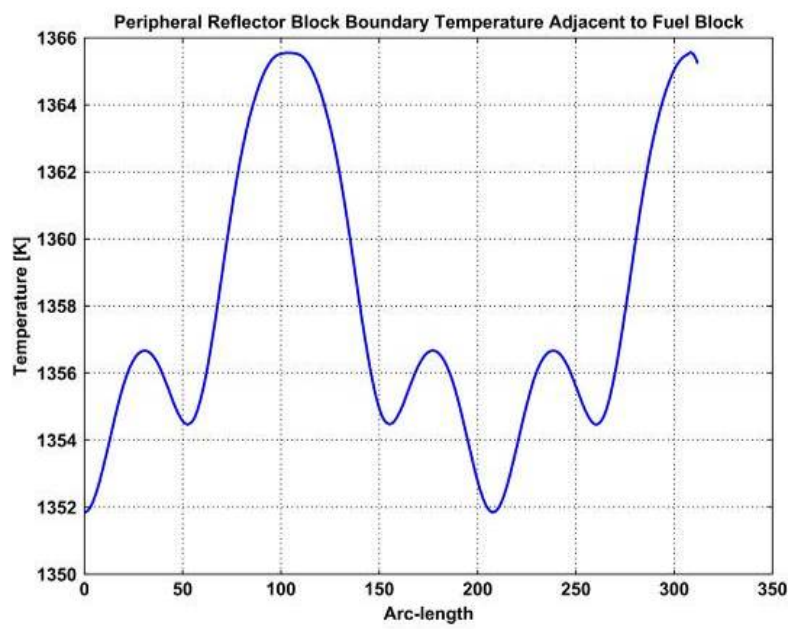

a

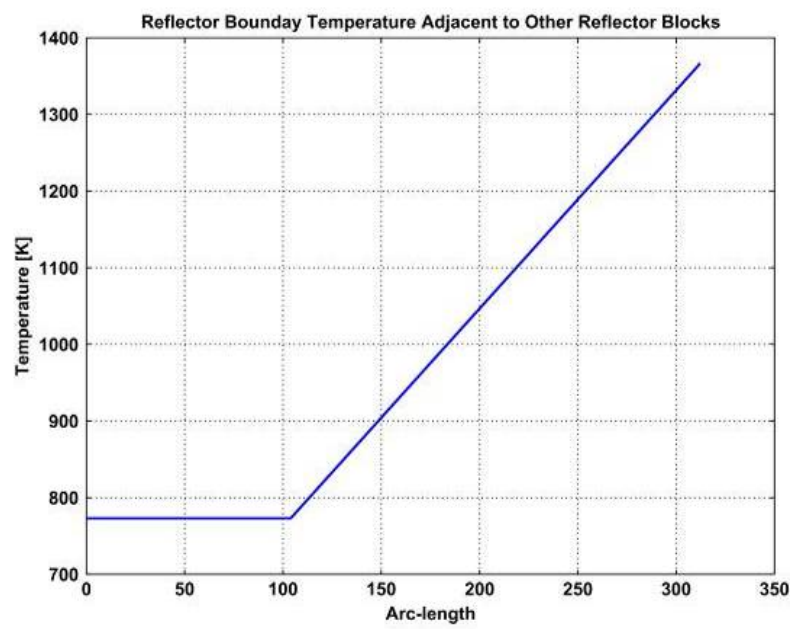

b

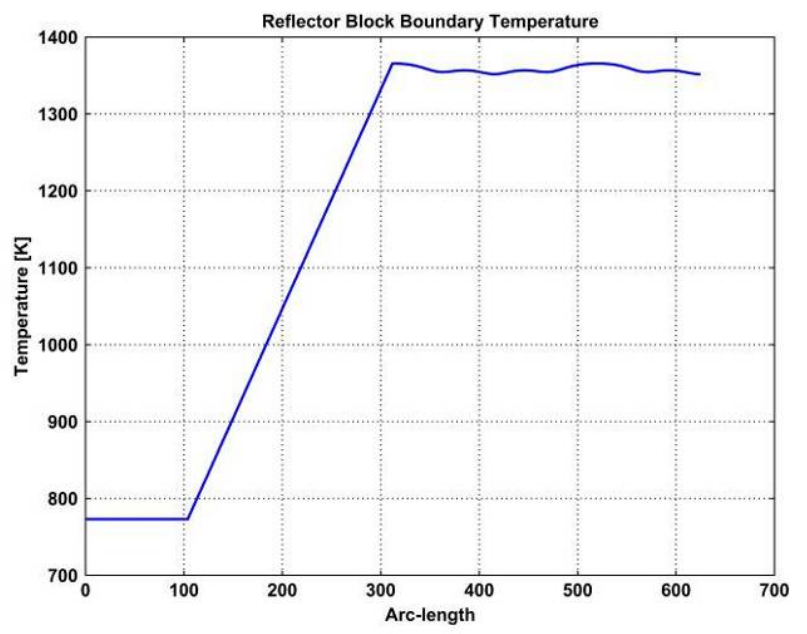

$\mathrm{C}$

Figure $22 \mathrm{a}, \mathrm{b}$, and c. Temperature imposed on the reflector cross-section boundaries. The arc length of the boundaries is in millimeters. 
Using these boundary conditions, the reflector cross-section's internal temperature distribution is shown in Figure 23. A large temperature gradient in the upper portion of the reflector cross-section is due to the adjacent fuel elements. The temperature drops quickly to the temperature on the bottom interface. This thermal gradient would likely create large thermally induced residual stresses in the upper portion of the block, especially next to the fuel elements. Improving the first approximation of a fixed temperature on the bottom interface and a linear temperature gradient to the midplane does not reduce the steeper gradient found in the upper portion of the reflector block adjacent to the fuel interface. From this work, the steep temperature gradients to a first approximation have been bounded and can be used to determine the effects on the material properties in the reflector cross section.

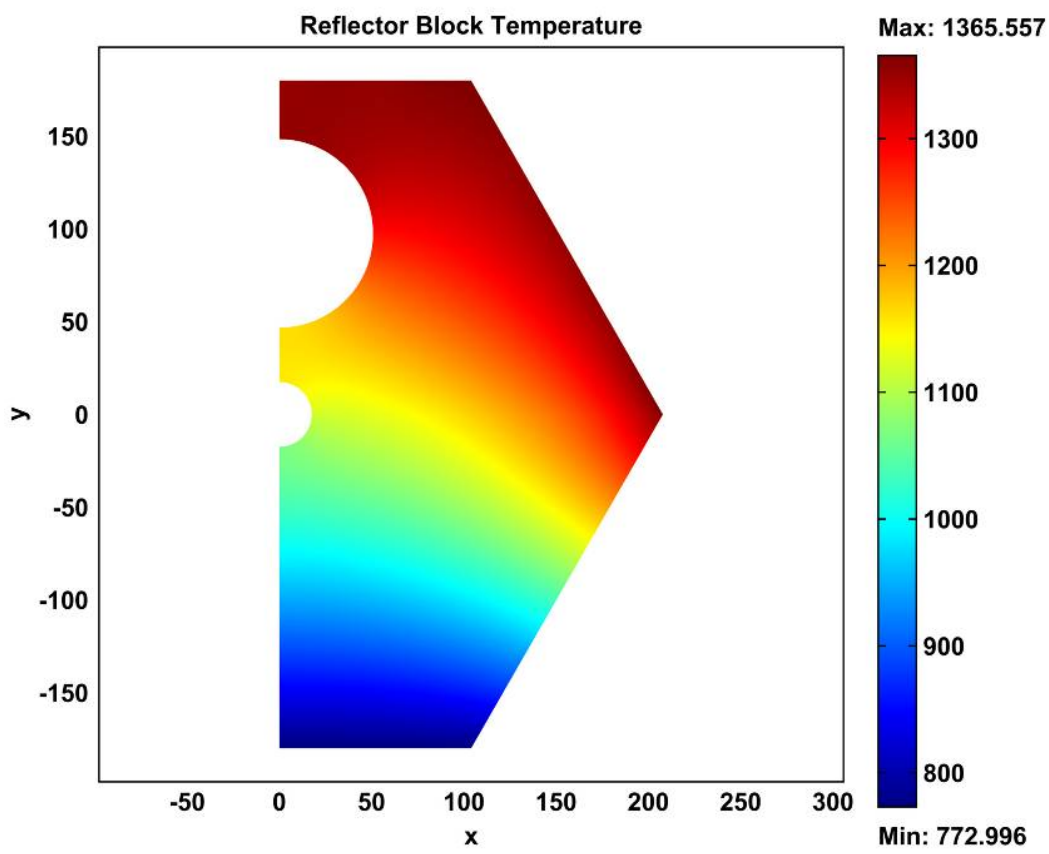

Figure 23. Temperature distribution in the reflector cross section with boundary temperatures imposed from the fuel elements. $\mathrm{X}$ and $\mathrm{Y}$ are the spatial dimensions of the model in millimeters.

Many simplifying assumptions were made in this analysis, and these assumed conditions may not actually exist in NGNP fuel elements. For example, it is expected the reflected albedo thermal neutron flux from the reflector crosssection will burn out the fuel compacts in adjacent fuel element cross section at a faster rate than burnup in the upper portion of the fuel element cross section. Therefore, temperature gradients in the fuel cross section can be expected. In addition, the fuel element cross section will contain interior zones where fuel compacts with different packing fractions will flatten the power across the fuel element. The reshuffling of the fuel blocks at refueling also may place fuel elements with different amounts of burnup around the reflector block creating different fast neutron gradients during each cycle. The use of burnable poisons compacts at the hexagon apexes and interior in the fuel element is dependent on the reactor vendor's design, which is not available at this time.

This analysis of the outer reflector can be used to guide the analysis of the inner reflector. The steep fast neutron fluence and temperature gradients affect the first 50 to 100 millimeters of the graphite cross section. The remaining graphite properties will remain virtually unchanged. The initial survey analysis of just the face on the inner reflector cross section can be accomplished using semi-analytical methods. Because no control rod channels are in the inner reflector, the blocks must only maintain geometry. 
Future sensitivity analysis on the reflector cross-section temperature distribution and stresses requires a viscoelastic neutron creep model. A neutron creep model for H-451 was developed from limited irradiation creep testing. The next section discusses the influence neutron viscoelastic creep has on graphite performance. 


\section{VISCOELASTIC GRAPHITE BEHAVIOR}

Graphite under a constant load or stress will demonstrate a viscoelastic behavior for which the magnitude depends on the temperature and neutron fast fluence. Figure 24 demonstrates viscoelastic behavior by an instantaneous application of a constant load or constant stress over a period of time while the strain in the material varies with time. After the load is applied, an initial elastic response or instantaneous strain is imparted in the specimen. As time increases the applied constant load causes the strain in the material to gradually increase; this is called creep. When the applied constant load is removed, the instantaneous elastic strain is recovered, and the creep strain decreases with time to a constant level. This is called creep recovery but the total strain is only partially recovered. The material now is permanently strained or deformed.
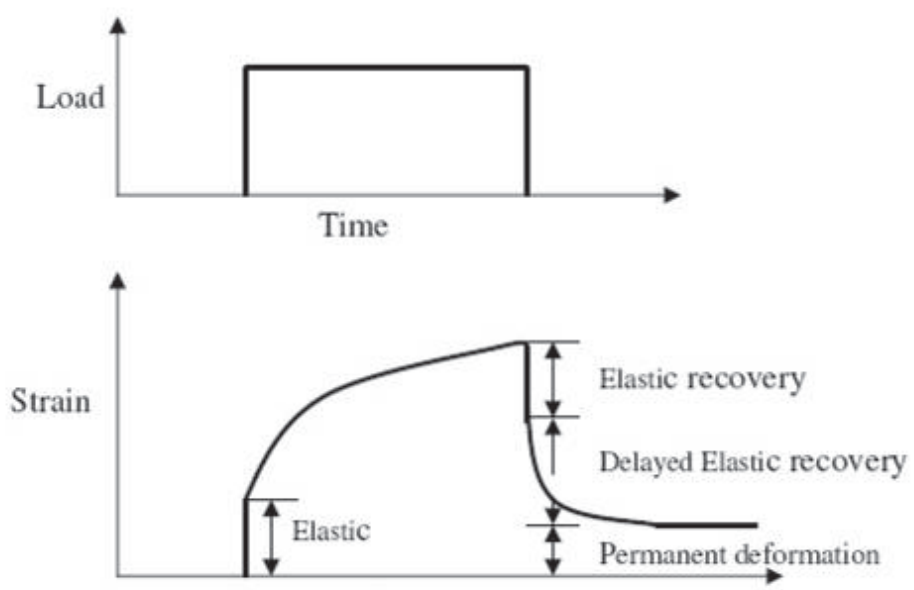

Time

Figure 24. Typical viscoelastic material creep behavior.

Creep testing has been performed on nonirradiated graphite at temperatures between 1,000 to $2,000^{\circ} \mathrm{C}{ }^{8}$ The testing demonstrated that the permanent creep strains are negligibly small compared to strains experienced in reactor operation. Permanent creep strains increase significantly in creep tests on nonirradiated graphite above $2,000^{\circ} \mathrm{C} .{ }^{9}$ Creep strains at these higher temperatures are classified as thermal creep strains. In this situation, the creep occurs when the graphite is held at a temperature for a significant amount of time. This is not the case when graphite is placed in a neutron field.

When graphite is under stress and placed in a neutron field with neutron energies above $0.1 \mathrm{MeV}$, the resulting crystalline damage from the elastic neutron scattering in the graphite crystal causes a reduction in the crystalline strain imparted by the applied stress. The crystalline damage or creep strain will occur independent of the irradiation temperature. The magnitude of the creep strain rate is proportional to the accumulated fast neutron fluence, the irradiation temperature, and stress loading. The neutron fluence is proportion to integration of the fast flux over time, and thus, the crystalline damage is denoted as a time dependent strain proportional to the fast neutron fluence or creep strain.

At the same time, the same neutron field is causing the graphite crystalline structure to decrease in volume imparting a permanent strain or deformation in the opposite sign of the creep strain. Without accounting for the creep strains, the stresses in the graphite block would increase at a rate that would necessitate premature replacement with its associated cost penalty. 
These competing effects along with thermal strains can create stresses that are higher than primary stresses from dead weight, pressure loading, or seismic loadings. If enough fast neutron fluence accumulates, these competing effects can cause the dimensions of the graphite blocks to distort. When the reactor shuts down, removing the neutron field, only a portion of the creep strain is recovered leaving a permanent creep strain or deformation. In conjunction with the permanent irradiation-induced strain, the resulting stress fields will instantaneous change sign at shutdown. If the magnitude of the stress reversal is severe enough fractures in the graphite block will occur. As the fast fluence accumulates in the blocks, the highest stresses in the block will be seen at shutdown. Thus a visoelastic model must be included in the finite element model to account for the changing stress fields with time and determine the lifetime of the graphite component.

The viscoelastic material model will be coupled to the local stress level in the graphite block, the local accumulated fast neutron fluence, and local irradiation temperature. The viscoelastic model requires material properties determined from irradiation creep testing performed at different irradiation temperatures under several different stress loadings sampled at fast neutron fluences from zero to the maximum fluence experienced in the core to perform the capability of predicting graphite core component lifetimes.

Further details of the viscoelastic graphite model will be provided in the future when the model has been incorporated into the current finite element model. 


\section{REFERENCES}

1. Department of Energy (DOE), "Evaluation of Graphite Stresses, Reliability and Life (Internals)," DOE/HTGR-86-058, June 1986.

2. General Atomics, "Gas Turbine Modular-Helium Reactor Conceptual Design Description Report," GA-910720, Revision 1, July 1996.

3. Philip E. MacDonald, James W. Sterbentz, Robert L. Sant, Paul D. Bayless, Richard R. Schultz, Hans D. Gougar, Richard L. Moore, Abderrafi M. Ougouag, William K. Terry, NGNP Point DesignResults of the Initial Neutronics and Thermal-Hydraulic Assessments During FY-03, INEEL/EXT-03-00870 Rev. 1, September 2003.

4. J. W. Sterbentz, "Calculated Neutron and Gamma-ray Spectra across the Prismatic Very High Temperature Reactor Core," Proceedings of the 13th International Symposium on Reactor Dosimetry, ISRD-13, Akersloot, The Netherlands, May 25-30, 2008.

5. DOE, “Graphite Design Handbook,” DOE-HTGR-88111, Rev. 0, September 1988.

6. COMSOL, COMSOL Multiphysics User Guide, Version 3.5a, 2008.

7. Y. Lejealil and M. T. Cabriillat, "Calcuation of thermal stresses in graphite fuel blocks," 18th International Conference on Structural Mechanics in Reactor Technology (SMiRT-18), Beijing, China August 7-12, 2005, paper SMiRT18-W101-3, pages 4786-4800.

8. W. L. Greenstreet, Mechanical Properties of Artificial Graphites - A Survey Report, ORNL-4327, December 1968.

9. C. E. Pugh, A Viscoelastic Representation of the Mechanical Behavior of RVD Graphite at Elevated Temperatures, ORNL-TM-2812, February 1970. 